\title{
The endocannabinoid system controls food intake via olfactory processes
}

\author{
Edgar Soria-Gómez ${ }^{1,2,12}$, Luigi Bellocchio ${ }^{3,12}$, Leire Reguero ${ }^{4}$, Gabriel Lepousez $^{5,6}$, Claire Martin ${ }^{7}$, \\ Mounir Bendahmane ${ }^{7}$, Sabine Ruehle ${ }^{8}$, Floor Remmers ${ }^{8}$, Tifany Desprez ${ }^{1,2}$, Isabelle Matias ${ }^{1,2}$, \\ Theresa Wiesner ${ }^{1,2}$, Astrid Cannich ${ }^{1,2}$, Antoine Nissant ${ }^{5,6}$, Aya Wadleigh ${ }^{1,2}$, Hans-Christian Pape ${ }^{9}$, \\ Anna Paola Chiarlone ${ }^{3}$, Carmelo Quarta ${ }^{10}$, Daniéle Verrier ${ }^{1,2}$, Peggy Vincent ${ }^{1,2}$, Federico Massa ${ }^{1,2}$, Beat Lutz ${ }^{8}$, \\ Manuel Guzmán ${ }^{3}$, Hirac Gurden ${ }^{7}$, Guillaume Ferreira ${ }^{11}$, Pierre-Marie Lledo ${ }^{5,6}$, Pedro Grandes ${ }^{4,13} \&$ \\ Giovanni Marsicano ${ }^{1,2,13}$
}

\begin{abstract}
Hunger arouses sensory perception, eventually leading to an increase in food intake, but the underlying mechanisms remain poorly understood. We found that cannabinoid type-1 $\left(\mathrm{CB}_{1}\right)$ receptors promote food intake in fasted mice by increasing odor detection. $\mathrm{CB}_{1}$ receptors were abundantly expressed on axon terminals of centrifugal cortical glutamatergic neurons that project to inhibitory granule cells of the main olfactory bulb (MOB). Local pharmacological and genetic manipulations revealed that endocannabinoids and exogenous cannabinoids increased odor detection and food intake in fasted mice by decreasing excitatory drive from olfactory cortex areas to the MOB. Consistently, cannabinoid agonists dampened in vivo optogenetically stimulated excitatory transmission in the same circuit. Our data indicate that cortical feedback projections to the MOB crucially regulate food intake via $\mathrm{CB}_{1}$ receptor signaling, linking the feeling of hunger to stronger odor processing. Thus, $\mathrm{CB}_{1}$ receptordependent control of cortical feedback projections in olfactory circuits couples internal states to perception and behavior.
\end{abstract}

It is a common experience that internal states can affect sensory perception, thereby regulating specific behaviors ${ }^{1-5}$. For instance, body and interoceptive signals can modulate time perception and consequent behaviors in humans ${ }^{2}$. One of the most prominent examples of these processes is the ability of hunger to increase olfactory performance to facilitate the retrieval and the ingestion of food ${ }^{4-8}$. However, the brain mechanisms governing the link between hunger, olfaction and food intake remain poorly understood. The endocannabinoid system is an important component of the central regulation of energy balance, and cannabinoid intoxication increases food intake ${ }^{9,10}$. Recently, the use of conditional mutant mice lacking the expression of the type-1 cannabinoid $\left(\mathrm{CB}_{1}\right)$ receptor (also known as $\mathrm{Cnr} 1$ ) from cortical glutamatergic neurons in the dorsal telencephalon, including neurons located in neocortex, paleocortex and archicortex (Glu- $\mathrm{CB}_{1}{ }^{-1-}$ ) revealed that (endo)cannabinoiddependent control of excitatory neurotransmission from cortical glutamatergic neurons is necessary to promote fasting-induced food intake ${ }^{11}$. Notably, cannabinoid drugs alter sensory perception, including olfaction ${ }^{12,13}$, suggesting a potential link between these two effects of brain (endo)cannabinoid signaling. However, the specific brain regions, neuronal circuits and mechanisms involved have not yet been identified. We addressed this issue and found that
$\mathrm{CB}_{1}$ receptor-dependent control of excitatory drive from centrifugal feedback projections to the olfactory bulb determines the efficiency of olfactory processes and food intake in fasted mice.

\section{RESULTS}

$\mathrm{CB}_{1}$ receptor expression in glutamatergic projections to the $\mathrm{MOB}$ As a result of the low levels of $\mathrm{CB}_{1}$ receptor expression in cortical glutamatergic neurons ${ }^{14,15}$, detailed anatomical analysis of $\mathrm{CB}_{1}$ receptor protein expression detected no or only minor differences between Glu- $\mathrm{CB}_{1}{ }^{-/-}$mice and wild-type littermates in many brain regions ${ }^{11,16}$ (data not shown). However, a clear reduction of $\mathrm{CB}_{1}$ receptor staining was evident in the MOB of mutant mice (Fig. 1a-e). In wild-type $\mathrm{MOB}, \mathrm{CB}_{1}$ receptor protein was virtually absent from the external plexiform layer and the mitral cell layer (MCL), was expressed at low levels in the glomerular layer, and was expressed at moderate levels in the internal plexiform layer (IPL; Fig. 1a,d). Conversely, $\mathrm{CB}_{1}$ receptor immunoreactivity was densely observed in the granule cell layer (GCL) of wild-type mice (Fig. 1a,d). In Glu- $\mathrm{CB}_{1}{ }^{-l-}$ mice, we detected a marked reduction of $\mathrm{CB}_{1}$ receptor immunoreactivity in the GCL (Fig. 1a,b,d-f and Supplementary Table 1), accompanied by a slight, decrease in the IPL (Fig. 1a,b,d-f and Supplementary Table 1). In the glomerular layer, the levels of $\mathrm{CB}_{1}$ protein staining were too

1INSERM, U862 NeuroCentre Magendie, Endocannabinoids and Neuroadaptation, Bordeaux, France. ${ }^{2}$ University of Bordeaux, NeuroCentre Magendie U862, Bordeaux, France. ${ }^{3}$ Department of Biochemistry and Molecular Biology I, School of Biology, Complutense University and CIBERNED, Madrid, Spain. ${ }^{4}$ Department of Neurosciences, Faculty of Medicine and Dentistry, University of the Basque Country UPV/EHU, Leioa, Spain. ${ }^{5}$ Laboratory for Perception and Memory, Institut Pasteur, Paris, France. ${ }^{6}$ CNRS UMR 3571, Paris, France. ${ }^{7}$ CNRS UMR 8165, IMNC, Univ. Paris Diderot \& Sud, Orsay, France. 8 Institute of Physiological Chemistry, University Medical Center of the Johannes Gutenberg University, Mainz, Germany. ${ }^{9}$ Institut fuer Physiologie I, Westfaelische Wilhelms-Universitaet, Muenster, Germany. ${ }^{10}$ Department of Medical and Surgical Sciences, University of Bologna, Bologna, Italy. ${ }^{11}$ INRA, Nutrition et Neurobiologie Intégrée, UMR 1286, Bordeaux, France. ${ }^{12}$ These authors contributed equally to this work. ${ }^{13}$ These authors jointly directed this work. Correspondence should be addressed to G.M. (giovanni.marsicano@inserm.fr). 
a

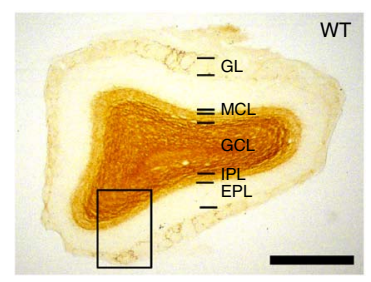

g

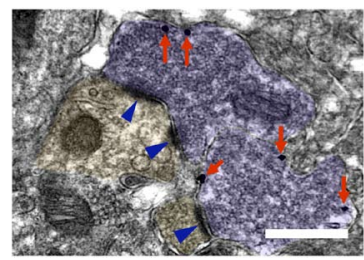

b

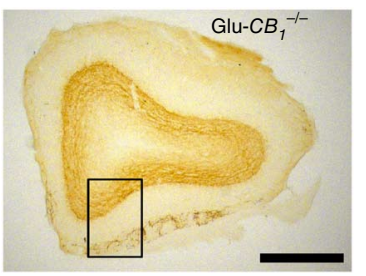

h

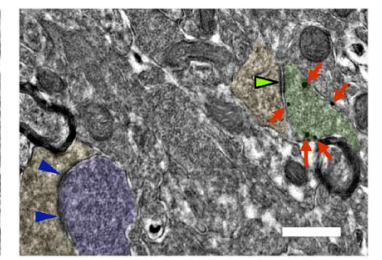

C

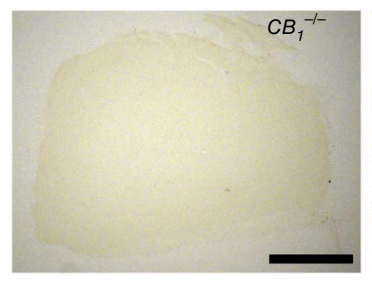

i

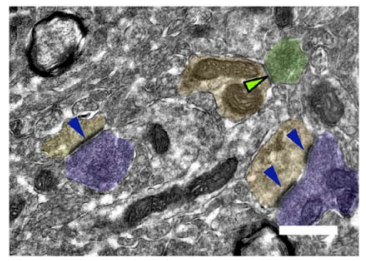

Figure $1 \mathrm{CB}_{1}$ receptor is expressed in centrifugal glutamatergic projections to the MOB. (a-c) Light microscopy of $\mathrm{CB}_{1}$ receptor immunohistochemistry in the MOB of wild-type (WT, a), Glu- $C B_{1}^{-1-}$ (b) and $C B_{1}^{-1-}$ mice (c). Representative images of 3 mice per genotype are shown. EPL, external plexiform layer; GL, glomerular layer. (d,e) Higher magnification of boxed regions in $\mathbf{a}$ and $\mathbf{b}$ showing $\mathrm{CB}_{1}$ expression in the different layers of the MOB in detail. (f) $\mathrm{CB}_{1}$ immunostaining quantification in the GCL and IPL of wild-type and Glu- $C B_{1}{ }^{-/-}$mice. Data are presented as mean \pm s.e.m. ${ }^{* *} P<0.01,{ }^{* * *} P<0.001$. See Supplementary Table 1 for detailed statistics. (g-i) Electron microscopy of immunogold staining for $\mathrm{CB}_{1}$ receptor in wild-type $(\mathbf{g})$, Glu- $C B_{1}^{-/-}(\mathbf{h})$ and $C B_{1}^{-/-}$(i) mice. Blue arrowheads indicate type-I asymmetric synapses and green arrowheads indicate type-II symmetric synapses. Red arrows point to $C B_{1}$ particles. (j,k) Micrographs of fluorescent in situ hybridization detecting $C B_{1}$ mRNA in the AON of wild-type (j) and Glu- $C B_{1}-1-$ mice $(\mathbf{k})(n=3$ per genotype). Lower panels are higher magnifications of the boxed AON regions in the top panels. PfCtx, prefrontal cortex. Scale bars represent $700 \mu \mathrm{m}(\mathbf{a}-\mathbf{c}), 0.5 \mu \mathrm{m}(\mathbf{g}-\mathbf{i})$ and $100 \mu \mathrm{m}(\mathbf{d}, \mathbf{e}, \mathbf{j}, \mathbf{k})$.

low to provide reliable quantitative data, but no evident alteration of expression was observed in Glu- $C B_{1}^{-/-}$mice (Fig. 1a,b,d,e). The GCL is mainly composed of inhibitory GABAergic neurons that receive important glutamatergic projections from cortical regions, including the anterior olfactory nucleus (AON) and the piriform cortex, which are known as the centrifugal glutamatergic innervation of the olfactory bulb ${ }^{17-20}$. Electron microscopy inspection revealed that the GCL contains mainly type I presumably excitatory asymmetric synapses, with a minority of type II presumably inhibitory symmetric synapses $^{18}$ (Fig. 1g-i). Semi-quantitative evaluation of immunogold labeling revealed that approximately $30 \%$ and $10 \%$ of total synaptic terminals contained $\mathrm{CB}_{1}$ receptor immunoparticles in the GCL of wild-type (281 counted terminals) and Glu- $\mathrm{CB}_{1}{ }^{-/-}$mice (143 counted terminals), respectively (Fig. 19,h). Approximately $1 \%$ of synapses displayed background staining in global $\mathrm{CB}_{1}^{-/-}$mice (143 counted terminals; Fig. 1i). In wild-type mice, more than $30 \%$ of unequivocally identified type I synapses were $\mathrm{CB}_{1}$ receptor immunopositive (108 counted terminals; Fig. 19). In both Glu- $C B_{1}^{-1-}$ and $C B_{1}^{-/-}$mice, less than $2 \%$ of type I synapses contained $\mathrm{CB}_{1}$ particles (52 and 73 counted terminals, respectively; Fig. 1h,i), suggesting that most of the $\mathrm{CB}_{1}$ receptors present at excitatory synapses are ablated in the $\mathrm{GCL}$ of Glu-CB${ }_{1}^{-/-}$mice.

$C B_{1}$ (Cnr1) mRNA was present at low levels in the MOB of wildtype mice (Supplementary Fig. 1). In particular, the transcript was present in sparse intrinsic dopaminergic (positive for tyrosine hydroxylase) and GABAergic neurons (expressing glutamic acid decarboxylase $65 \mathrm{kDa}$, GAD65), but not in glutamatergic neurons (positive for vesicular glutamate transporter 1, VGluT1), of different layers of the MOB (Supplementary Fig. 1). However, Glu- $C B_{1}^{-/-}$ mice did not display any evident reduction of $C B_{1}$ mRNA levels in any of the MOB subpopulations (Supplementary Fig. 1). Conversely, $C B_{1}$
mRNA was abundantly present in the AON (Fig. 1j). In cortical areas, including the $A O N, C B_{1}$ mRNA is expressed in two main neuronal populations ${ }^{14,21-23}$ : approximately half of GABAergic interneurons contain very high levels of the transcript, whereas the majority of pyramidal glutamatergic neurons display moderate-to-low levels of $C B_{1}$ mRNA $^{14,21-23}$. Similarly to other cortical areas ${ }^{11,23}$, the AON of Glu- $C B_{1}^{-/-}$mice contained cells expressing high levels of $C B_{1}$ mRNA (presumably GABAergic), whereas low-to-moderate $\mathrm{CB}_{1}$ receptorexpressing neurons were not detectable (Fig. 1k), confirming the specific deletion of $C B_{1}$ in cortical glutamatergic neurons ${ }^{21-23}$.

Thus, presynaptic $\mathrm{CB}_{1}$ receptors ${ }^{14,24,25}$ in the $\mathrm{MOB}$ reside mostly on axon terminals of cortical glutamatergic centrifugal projections, which are primarily located in the GCL and partly in the IPL. Altogether, these data suggest that $\mathrm{CB}_{1}$ receptor modulation of fasting-induced food intake might involve the control of feedback glutamatergic projections from cortical olfactory areas to the MOB.

\section{$\mathrm{CB}_{1}$ in the MOB is necessary for hyperphagia after fasting}

As expected ${ }^{26}$, a 24 -h fast increased the levels of the endocannabinoid anandamide (AEA) in the hypothalamus, but not in the cerebellum of C57BL/6N mice (Supplementary Fig. 2 and Supplementary Table 2). Notably, a similar increase of AEA levels was also observed in the olfactory bulb of fasted mice (Fig. 2a and Supplementary Table 1), whereas the levels of the other main endocannabinoid, 2-arachidonoyl-glycerol (2-AG), were not altered (Fig. 2a, Supplementary Fig. 2, and Supplementary Tables 1 and 2). Notably, local infusion of the $\mathrm{CB}_{1}$ receptor antagonist $\mathrm{AM} 251$ (4 $\mu$ g per side) into the GCL of fasted C57BL/6N mice before re-feeding substantially decreased food intake (Fig. 2b, Supplementary Fig. 3, and Supplementary Tables 1 and 2 ), indicating that $\mathrm{CB}_{1}$ receptor activation in the GCL is necessary for fasting-induced food intake. To determine 
Figure 2 Endocannabinoid signaling in the MOB is activated by fasting and promotes food intake by dampening glutamatergic transmission. (a) Anandamide and 2-AG levels in the $\mathrm{MOB}$ of control and 24-h fasted C57BL/6N mice. (b) Food intake of 24-h fasted C57BL/6N mice injected intra-MOB with vehicle or AM251 (4 $\mu$ g per side). (c) Food intakes of fasted wild-type and Glu-CB ${ }_{1}^{-/-}$littermates injected intra-MOB with vehicle or MK801 (1 or $2 \mu$ g per side). (d) Left, representative micrographs of c-Fos expression in MOB of control and fasted Glu-CB $1^{-/-}$mice and wild-type littermates. Right, quantification of c-Fos-positive cells in mitral cell layer, glomerular layer and granule cell layer cells of the MOB. Scale bar represents $500 \mu \mathrm{m}$. Data are presented as mean \pm s.e.m. ${ }^{*} P<0.05,{ }^{* *} P<0.01,{ }^{* * *} P<0.001$. See Supplementary Table 1 for detailed statistics.

whether endocannabinoid signaling in the GCL regulates food intake through inhibition of glutamatergic transmission, we infused the NMDA receptor antagonist MK801 ( 1 or $2 \mu \mathrm{g}$ per side) into the GCL of wild-type and Glu-CB $B_{1}^{-1-}$ littermates. As expected ${ }^{11}$, vehicle-treated mutant mice ate less than control mice (Fig. 2c and Supplementary Table 1). However, intra-GCL injections of MK801 dose-dependently abolished the phenotype of Glu-CB ${ }_{1}^{-/-}$littermates (Fig. 2c and Supplementary Table 1), indicating that this phenotype is a result of excessive glutamatergic signaling in the MOB. To further corroborate this idea, we checked the effects of fasting on neuronal activation in the MOB of wild-type and Glu-CB ${ }_{1}^{-1-}$ littermates. Staining of the early immediate gene $c$-Fos (a widely used marker of neuronal activation) revealed that 24-h fasting did not induce any measurable alteration of neuronal activity in the MCL or the glomerular layer of the MOB (Fig. 2d and Supplementary Table 1), or in the AON (data not shown) of wildtype control mice. In contrast, 24-h fasting strongly decreased c-Fos staining in the GCL of wild-type mice, but not in the corresponding area of mutant Glu-CB${ }_{1}^{-/-}$littermates (Fig. 2d and Supplementary Table 1), indicating that $\mathrm{CB}_{1}$ receptors on glutamatergic terminals in the GCL are required for the fasting-induced decrease of activity of GCL neurons. Overall, these data indicate that the orexigenic functions of the endocannabinoid system after fasting involve a reduction
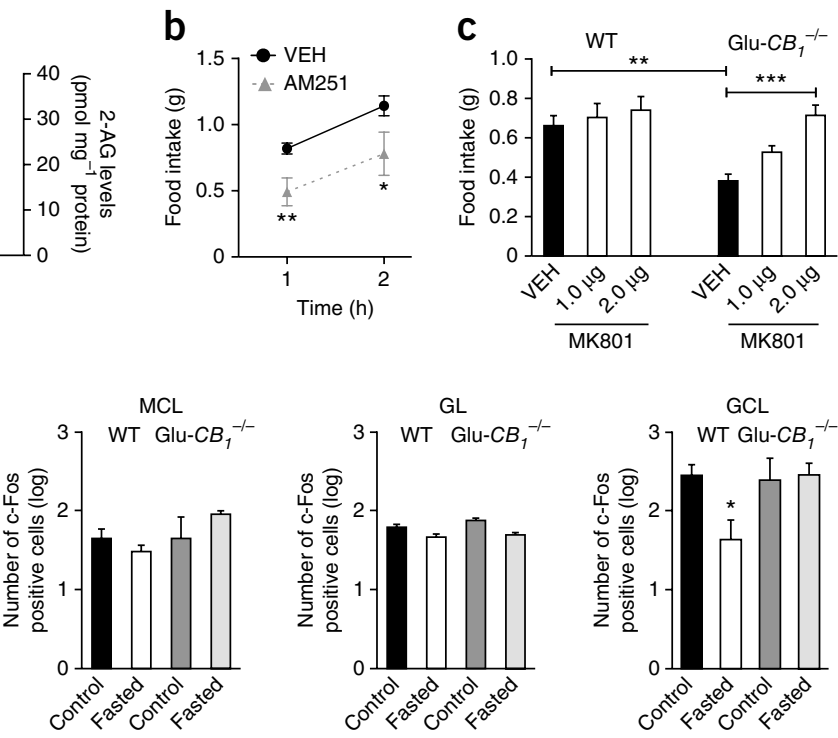

of glutamatergic transmission in the $\mathrm{MOB}$, mediated by $\mathrm{CB}_{1}$ receptors expressed at corticofugal terminals.

\section{$\mathrm{CB}_{1}$ in the MOB is sufficient for hyperphagia after fasting}

In Glu- $C B_{1}^{-1-}$ mice, $C B_{1}$ is deleted in glutamatergic neurons of many cortical areas ${ }^{11,23}$. To limit the deletion to specific olfactory cortical regions, we injected an adeno-associated virus encoding Cre recombinase (AAV-Cre) into the $\mathrm{AON}$ and the anterior piriform cortex (APC) of mice carrying a loxP-flanked $C B_{1}$ gene $\left(C B_{1} \text {-flox }\right)^{23,27,28}$ to generate mice displaying an almost complete absence of $\mathrm{CB} 1 \mathrm{mRNA}$ in the injected brain region ( $\mathrm{AON}$ / APC- $C B_{1}^{-1-}$ mice; Fig. 3a). Notably, AON/APC- $C B_{1}^{-1-}$ mice had significantly reduced $C_{1}$ receptor protein at centrifugal glutamatergic terminals in the GCL (Fig. 3b,c and Supplementary Table 1), but not in the IPL (Supplementary Fig. 4 and Supplementary Table 2) or in the glomerular layer (Fig. 3b). AON/APC- $C B_{1}^{-1-}$ mice displayed a clear hypophagic phenotype in fasting-re-feeding conditions, very similar to Glu- $C B_{1}^{-l-}$ and $C B_{1}^{-l-}$ mice ${ }^{12}$ (Fig. 3d and Supplementary Table 1). Notably, a clear positive correlation was observed between the levels of $\mathrm{CB}_{1}$ receptor expression in the GCL (but not in the IPL) and food intake (Fig. 3e, Supplementary Fig. 4, and

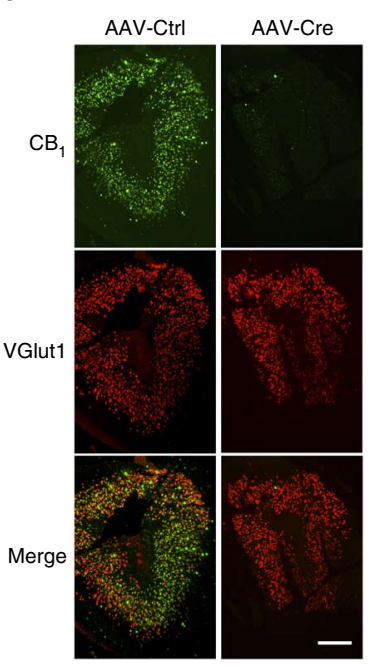

b
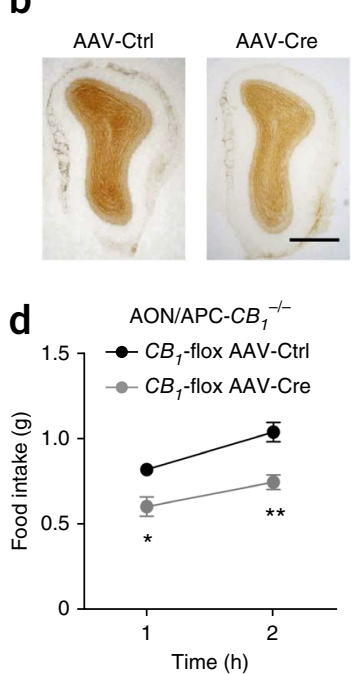

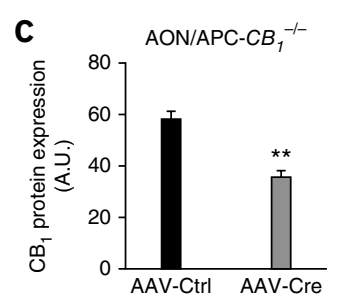

e

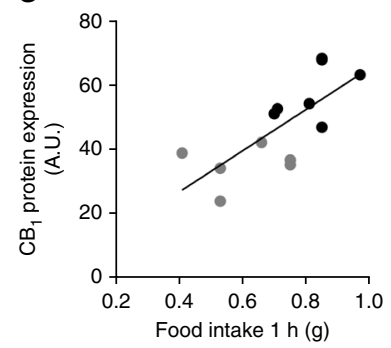

Figure $3 \mathrm{CB}_{1}$ receptors on GCL-projecting feedback glutamatergic cortical neurons are necessary for fasting-induced hyperphagia. (a) Micrograph showing fluorescent in situ hybridization of $\mathrm{CB}_{1}$ receptor and VGlut1 mRNA in the $A O N$ of $C B_{1}$-flox mice injected intra-AON with an empty AAV (AAV-Ctrl) or AAV-Cre. Scale bar represents $500 \mu \mathrm{m}$. (b,c) $\mathrm{CB}_{1}$ receptor immunohistochemistry (b) and semi-quantification (c) in the GCL of the MOB of $C B_{1}$-flox AAV-Ctrl (AAV-Ctrl) and AON/APC- $C B_{1}^{-1-}$ mice $\left(C B_{1}\right.$-flox AAV-Cre). (d) Food intakes of $C B_{1}$-flox-AAV-Ctrl and AON/APC- $C B_{1}^{-1-}$ mice. (e) Correlation between the levels of $C B_{1}$ protein expression in the GCL of the MOB and food intake in $C B_{1}$-floxAAV-Ctrl (black symbols) and AON/APC- $C B_{1}^{-1-}$ mice (gray symbols). Values are the same as in c and d. VGlut1, vesicular glutamate transporter-1. Data are presented as mean \pm s.e.m. ${ }^{*} P<0.05$, $* * P<0.01$. Scale bars represent $500 \mu \mathrm{m}$. See Supplementary Table 1 for detailed statistics. 
Figure $4 \mathrm{CB}_{1}$ receptors on GCL-projecting feedback glutamatergic cortical neurons are sufficient for fasting-induced hyperphagia. (a) Representative images (7-12 mice per group, 4-5 images per mouse) of $\mathrm{CB}_{1}$ receptor immunohistochemistry in the MOB of wild-type, Stop- $C B_{1}, C B_{1}$-RS and Glu- $C B_{1}$-RS mice. Scale bar represents $500 \mu \mathrm{m}$. (b) Cumulative food intakes of 24-h fasted wild-type, Stop- $C B_{1}, C B_{1}$-RS and Glu- $C B_{1}$-RS mice. (c) Representative images (5-7 mice per group, 4-5 images per mouse) of $C_{1}$ receptor immunohistochemistry in the $A O N$ and $M O B$ of Stop- $C B_{1}$ mice after local intra-AON injection of an empty AAV (AAV-Ctrl mice) or AAV-Cre (AON/APC-CB - -RS mice). Scale bars represent $500 \mu \mathrm{m}$. (d) Cumulative food intake of 24-h fasted Stop- $C B_{1}$ (AAV-Ctrl) and AON/APC- $C B_{1}$-RS mice. Data are presented as mean \pm s.e.m. ${ }^{*} P<0.05$, ${ }^{* *} P<0.01$. See Supplementary Table 1 and for detailed statistics.

Supplementary Tables 1 and 2). Thus, $\mathrm{CB}_{1}$ receptors on feedback centrifugal glutamatergic cortical neurons to the GCL of the MOB are necessary for fasting-induced hyperphagia.

Causality is determined by necessity and/or sufficiency relationships between events. Thus, to determine whether $\mathrm{CB}_{1}$ receptor signaling in corticofugal axons has a sufficient role in fasting-induced food intake, we used the Cre-loxP system to obtain conditional rescue of $\mathrm{CB}_{1}$ receptor expression ${ }^{29}$. The $C B_{1}$ receptor allele was genetically modified by introducing a lox $P$-flanked stop cassette preceding the open reading frame of the gene to generate the Stop- $C B_{1}$ mouse line ${ }^{29}$. Similar to conventional $C B_{1}^{-/-}$mice, these mice fully lacked the expression of the $\mathrm{CB}_{1}$ receptor protein ${ }^{29}$ (Supplementary Fig. 5). However, in the presence of Cre recombinase, the loxP-flanked stop cassette was excised and the $\mathrm{CB}_{1}$ receptor protein was conditionally re-expressed in rescued mice ${ }^{29}$ (Supplementary Fig. 5). As in other brain regions ${ }^{29}$ (Supplementary Fig. 5), Stop- $C B_{1}$ mice lacked $\mathrm{CB}_{1}$ receptor protein expression in olfactory areas (Fig. 4a), whereas the immunohistochemical staining pattern was indistinguishable from that of wild-type in mice carrying a global restoration
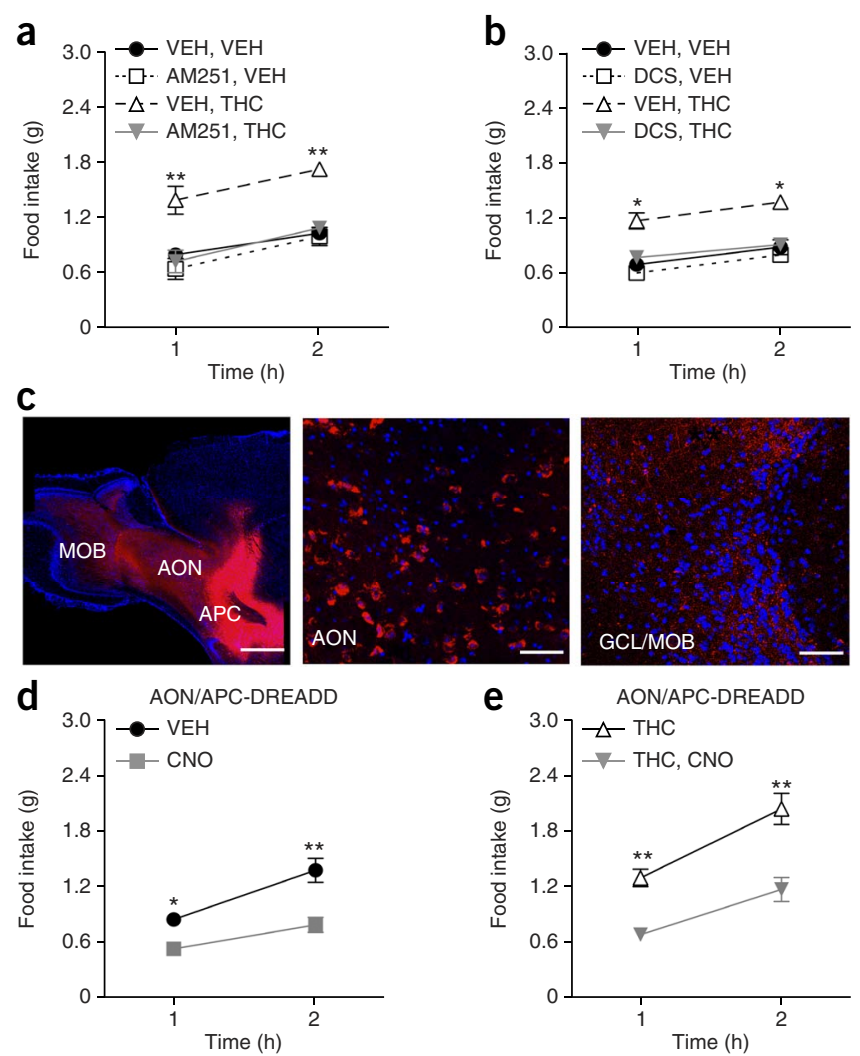

a
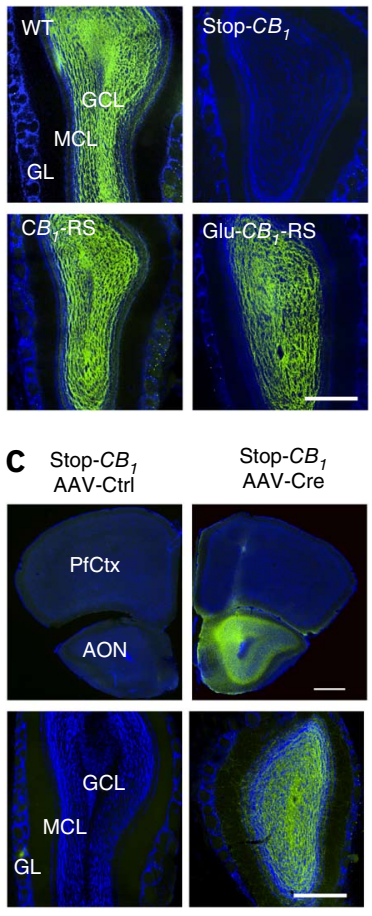

b

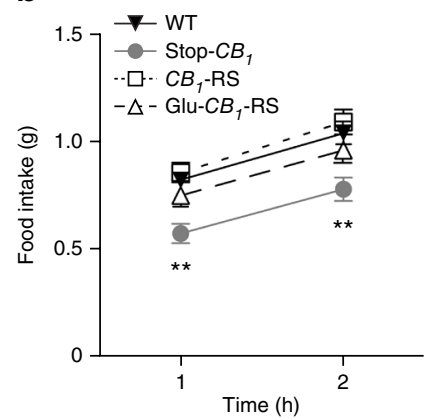

d

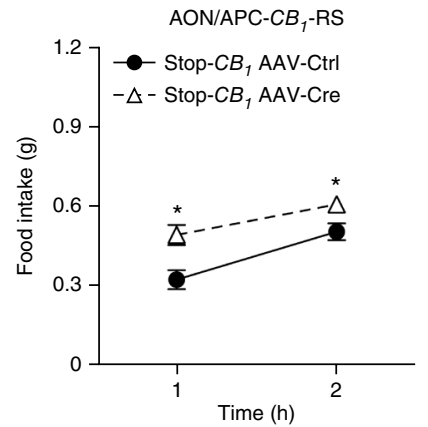

of $\mathrm{CB}_{1}$ receptor expression $\left(\mathrm{CB}_{1}\right.$-RS mice; Online Methods, Fig. 4a and Supplementary Fig. 5). Crossing Stop- $C B_{1}$ mice with Nex-Cre mice ${ }^{23,30}$ (Online Methods) to delete the stop cassette in cortical glutamatergic neurons led to the re-expression of $\mathrm{CB}_{1}$ protein in these neurons ${ }^{29}$ (Glu- $C B_{1}$-RS mice; Supplementary Fig. 5), including centrifugal glutamatergic terminals in the GCL (Fig. 4a). Similar to conventional $C B_{1}{ }^{-1-}$ mice (refs. 11 and 26), Stop-CB mice were hypophagic in fasting-re-feeding conditions (Fig. 4b), whereas littermate Glu- $\mathrm{CB}_{1}$-RS mice displayed food intake levels that were not different from those of fully rescued $C B_{1}$-RS or wild-type control mice (Fig. $4 \mathbf{b}$ and Supplementary Table 1 ). These results indicate that $\mathrm{CB}_{1}$ receptors in cortical glutamatergic neurons are sufficient to provide normal fasting-induced food intake.

However, the Glu- $C B_{1}-\mathrm{RS}$ mice express $\mathrm{CB}_{1}$ receptors in glutamatergic neurons not only in olfactory circuits (Fig. 4a), but also in many other brain region ${ }^{29}$ (Supplementary Fig. 5). To limit the rescue approach to more specific olfactory circuits, similar to the AON/APC- $\mathrm{CB}_{1}{ }^{-1-}$ mice described above, we injected AAV-Cre into the AON/APC of Stop- $C B_{1}$ mice to generate AON/APC- $C B_{1}$-RS mice. This treatment restored the expression of the $\mathrm{CB}_{1}$ receptor protein in the GCL (Fig. 4c) and increased food intake compared with Stop- $C B_{1}$ littermates

Figure 5 Centrifugal glutamatergic transmission in the MOB mediates fasting-induced food intake and the hyperphagic effect of THC in C57BL/6N mice. (a,b) Intra-MOB injections of sub-effective doses of AM251 ( $2 \mu \mathrm{g}$ per side, a) and DCS ( $2 \mu \mathrm{g}$ per side, b) blocked the hyperphagic effect of THC (1 mg per $\mathrm{kg}$ ) in C57BL/6N fasted mice. $\mathrm{VEH}$, vehicle. (c) Injection of AAV-CaMK-mCherry (red) into the AON determined infection of centrifugal neurons (left and middle) sending projections to the GCL (left and right). Scale bars represent $500 \mu \mathrm{m}$ (left) and $110 \mu \mathrm{m}$ (middle and right). Blue, DAPI counterstaining; red, mCherry. (d,e) Injection of AAV-CaMK-DREADD into the AON (AON/APC-DREADD) and treatment with CNO decreased food intake (d) and blocked the hyperphagic effect of THC (e) in fasted C57BL/6N mice. Data are presented as mean \pm s.e.m. ${ }^{*} P<0.05,{ }^{* *} P<0.01$.

See Supplementary Table 3 for detailed statistics. 
Figure $6 \mathrm{CB}_{1}$ receptor activation decreases olfactory habituation in fasted mice. (a) Olfactory habituation under vehicle or THC treatment (1 mg per kg). $(\mathbf{b}, \mathbf{c})$ Habituation indexes under vehicle or THC treatment in fasted Glu- $C B_{1}{ }^{-/}$mice and wild-type littermates (b) and in wild-type mice injected intra-MOB with DCS ( $2 \mu \mathrm{g}$ per side, $\mathbf{c})$. Data are presented as mean \pm s.e.m. ${ }^{* *} P<0.01,{ }^{* *} P<0.001$. See Supplementary Table 3 for detailed statistics.

treated with a control AAV (Fig. 4d and Supplementary Table 1). For unknown reasons, lower levels of food intake were consistently observed in Stop- $C B_{1}$ mice, which underwent surgery for local virus infusion, compared with intact mice of the same genotype (Fig. 4b,d). However, the relative rescue of the hypophagic phenotype of respective Stop- $C B_{1}$ control mice was similar in $C B_{1}$-RS, Glu-CB $-\mathrm{RS}$ and $\mathrm{AON} / \mathrm{APC}-\mathrm{CB} B_{1}$-RS mice (Supplementary Fig. 5). These data indicate that $\mathrm{CB}_{1}$ receptor expression in corticofugal pathways to the $\mathrm{MOB}$ is necessary and sufficient to promote fasting-induced food intake.

\section{$\mathrm{CB}_{1}$ controls feeding via olfactory corticofugal circuits}

Exogenous administration of the plant-derived $\mathrm{CB}_{1}$ receptor agonist $\Delta^{9}$-tetrahydrocannabinol (THC) at low doses ( $1 \mathrm{mg}$ per $\mathrm{kg}$ of body weight) enhanced fasting-induced food intake in wild-type mice ${ }^{11}$ (Fig. 5a,b and Supplementary Table 3). This effect was fully blocked by the local infusion of a sub-effective dose of the $\mathrm{CB}_{1}$ receptor antagonist AM251 (2 $\mu \mathrm{g}$ per side; Fig. 5a and Supplementary Table 3) or of the allosteric NMDA receptor enhancer D-cycloserine (DCS)

a
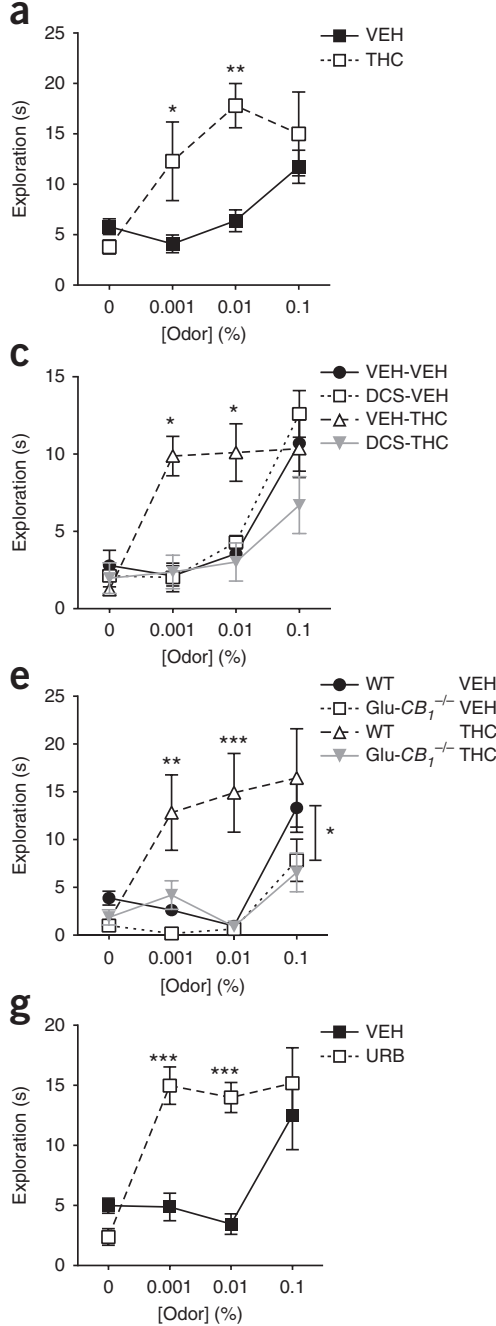

b
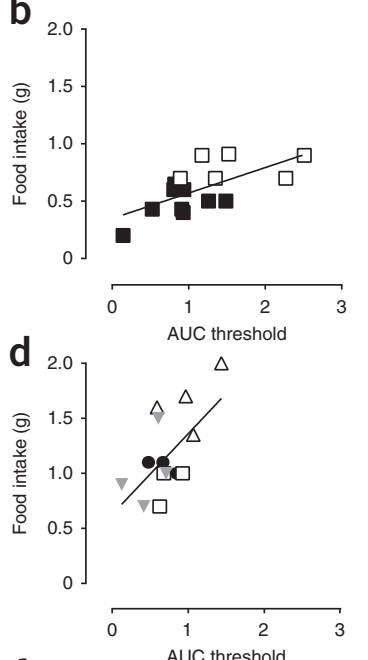

f

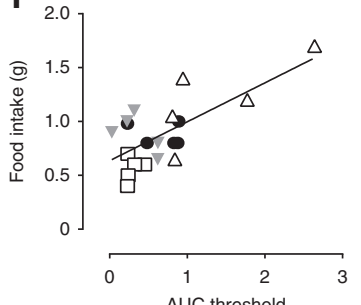

h

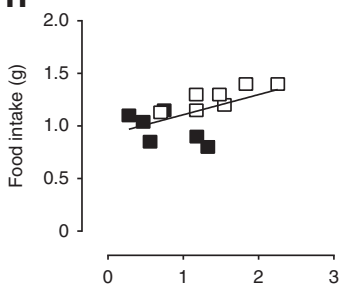

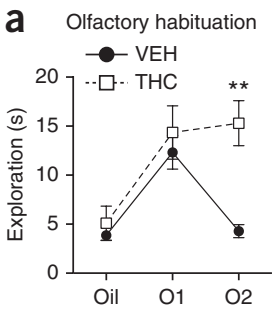
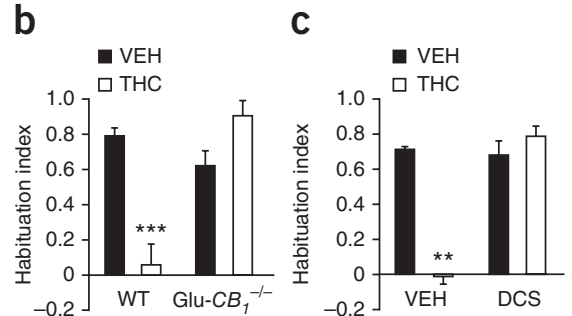

into the GCL ( $2 \mu$ g per side; Fig. 5 b and Supplementary Table 3), as previously shown with systemic treatments ${ }^{11}$. Thus, the hyperphagic effect of THC requires activation of $\mathrm{CB}_{1}$ receptors and inhibition of glutamatergic transmission in the GCL, suggesting that centrifugal excitation of the GCL is inversely correlated to food intake in fasted animals. To directly test this hypothesis, we injected an AAV expressing a designer receptor exclusively activated by designer drugs $\left(\mathrm{G}_{\mathrm{q}} \text {-DREADD }\right)^{31,32}$ under the control of a minimal Camk2a promoter (AAV-CaMK-DREADD) or a control AAV expressing the fluorescent protein mCherry in the AON/APC region of $\mathrm{C} 57 \mathrm{BL} / 6 \mathrm{~N}$ mice to obtain AON/APC-DREADD mice (Fig. 5c and Supplementary Fig. 6). The specific $\mathrm{G}_{\mathrm{q}}$-DREADD synthetic agonist clozapine- $N$ oxide $(\mathrm{CNO})$, which activates neurons expressing $\mathrm{G}_{\mathrm{q}}$-DREADD ${ }^{32}$ (Supplementary Fig. 6), did not alter food intake in control AAV-injected mice (Supplementary Fig. 6). However, AON/APCDREADD mice displayed a strong hypophagia after CNO treatment (Fig. 5d and Supplementary Table 3). Notably, the CNO treatment also abolished the hyperphagic effect of THC in the same conditions (Fig. 5e and Supplementary Table 3).

\section{$\mathrm{CB}_{1}$ signaling in the $\mathrm{MOB}$ couples olfaction to feeding}

We next investigated whether $\mathrm{CB}_{1}$ receptor signaling in the $\mathrm{MOB}$ modulates food intake by altering olfactory processes in 24 -h fasted C57BL/6N mice. First, we measured olfactory habituation by exposing the mice twice to the same odor (almond or banana, diluted at $0.1 \%$, widely used as attractive, but food-unrelated, odors for rodents) $)^{33}$ and scoring their exploration of the source of the odor. As expected ${ }^{33-35}$, vehicle-treated mice displayed increased exploration of the odor compared with those treated with an odorless oil control (Fig. 6a). These values returned to control levels (oil) at the second exposure to the same odor (Fig. 6a), indicating habituation to olfactory stimuli ${ }^{33-35}$. Notably, THC (1 mg per kg) impaired olfactory habituation in wildtype mice (Fig. 6a-c, Supplementary Fig. 7, and Supplementary Tables 2 and 3), but not in Glu- $C B_{1}^{-l-}$ mice (Fig. 6b, Supplementary Fig. 7, and Supplementary Tables 2 and 3) or in mice receiving an intra-GCL injection of DCS (Fig. 6c, Supplementary Fig. 7, and Supplementary Tables 2 and 3 ).

These results apparently suggest that the decrease of olfactory habituation might represent a causal link between $\mathrm{CB}_{1}$ receptor-dependent control of glutamatergic transmission in the GCL and food intake.

Figure $7 \mathrm{CB}_{1}$ receptor signaling in the $\mathrm{MOB}$ enhances olfactory detection in fasted mice and proportionally promotes food intake. $(\mathbf{a}, \mathbf{c}, \mathbf{e}, \mathbf{g})$ Exploration of increasing concentrations of an odor (almond or banana) under vehicle or THC treatment (1 mg per $\mathrm{kg}$ ) in C57BL/6N (a), in wild-type mice injected intra-MOB with DCS ( $2 \mu$ g per side) (c), in Glu-CB ${ }_{1}^{-l-}$ mice and wild-type littermates (e), and in wild-type mice systemically injected with URB597 (URB, $10 \mathrm{mg}$ per kg, g). (b,d,f,h) Significant correlations were detected between food intake and area under the curve (AUC) of odor detection threshold (data from a, c,e,g). Data are presented as mean \pm s.e.m. ${ }^{*} P<0.05,{ }^{* *} P<0.01,{ }^{* * *} P<0.001$. See Supplementary Table 3 for detailed statistics. 


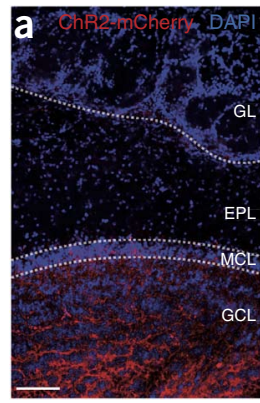

b

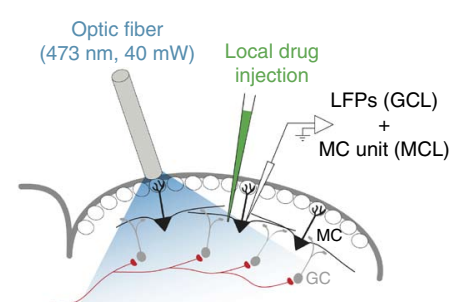

ChR2 ${ }^{+}$AON/APC axon terminals
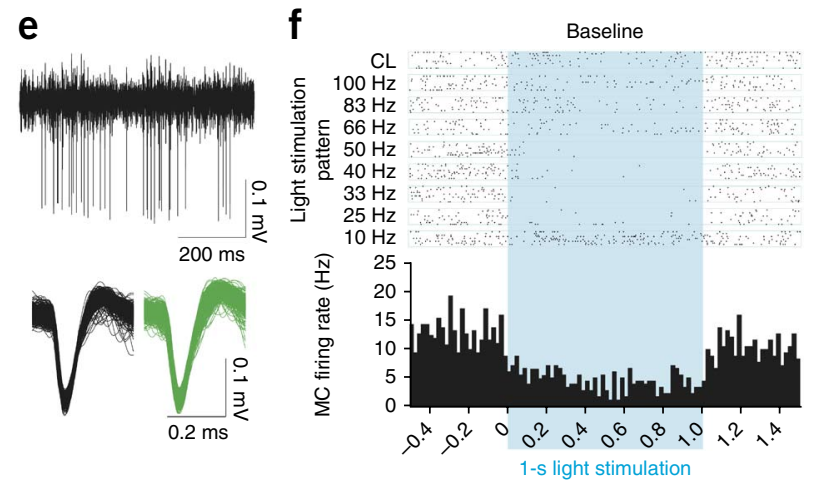

C

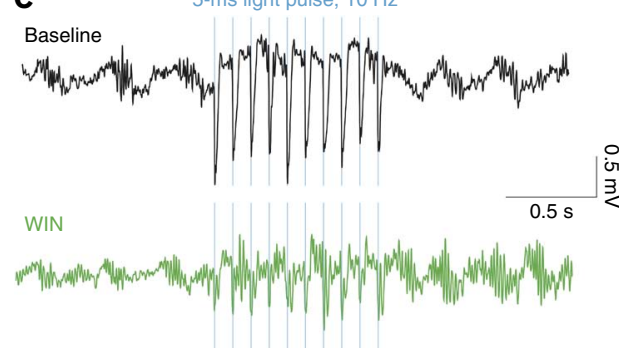

d

Baseline

WIN (4.2 ng, $n=12)$

VEH (saline $+10 \%$ DMSO, $n=7$ )

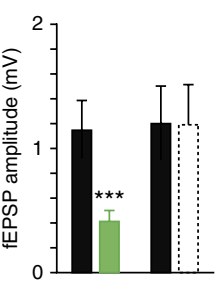

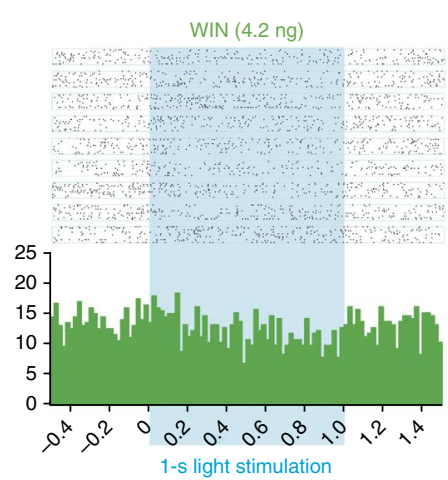

g

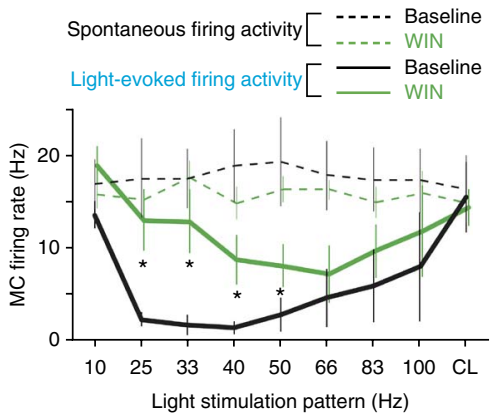

Figure $8 \mathrm{CB}_{1}$ receptors control synaptic activity in the corticofugal system. (a) ChR2 (red) expression in the GCL of mice injected with AAV-ChR2-mCherry into the AON/APC. Scale bar represents $500 \mu \mathrm{m}$. (b) Schematic representation of the methodological approach. Extracellular fEPSPs in the GCL and mitral cell (MC) unit recordings in the MCL of the MOB in awake head-fixed mice in response to the selective light stimulation of ChR2+ $A O N / A P C$ axon terminals in the MOB. (c,d) Local injection of the $\mathrm{CB}_{1}$-receptor agonist WIN 55,212-2 (WIN, $4.2 \mathrm{ng}$ ) induced a strong decrease in the amplitude of the light-evoked fEPSP. (e-g) $C_{1}$ receptor signaling influenced output mitral cell activity. (e) Top, spontaneous mitral cell single-unit firing activity. Bottom, spike waveform and amplitude during baseline (left) and after WIN (right). AON/APC axon stimulation inhibited mitral cell spontaneous firing in a frequency-dependent manner ( $\mathbf{f}$ left, $\mathbf{g}$ ). Local infusion of WIN (4.2 ng) decreased the magnitude of light-evoked feed forward inhibition of mitral cell firing (f right, g). Data are presented as mean \pm s.e.m. ${ }^{*} P<0.05,{ }^{* *} P<0.001$. See Supplementary Table 3 for detailed statistics.

However, when food intake was measured after olfactory habituation, there was no correlation between food intake and exploration (data not shown). Moreover, it is important to note that Glu-CB ${ }^{-/-}$ mice, in addition to not responding to THC, did not show any evident spontaneous phenotype in olfactory habituation experiments (Fig. 6b, Supplementary Fig. 7, and Supplementary Tables 2 and 3), whereas they were hypophagic. Thus, alterations of olfactory habituation likely represent a parallel effect of THC, which might be unrelated to food intake (lack of positive correlation) and might not be physiologically regulated by endocannabinoid signaling (lack of phenotypic alteration of Glu-CB $B_{1}^{-1-}$ mice).

To find additional (endo)cannabinoid-dependent olfactory processes, which might reliably explain the control of fasting-induced food intake, we measured threshold for odor detection as an index of odor sensitivity ${ }^{34}$. After scoring baseline exploration of odorless oil, mice were exposed to increasing concentrations of the same odor (almond or banana ${ }^{33}$, from $0.001 \%$ to $0.1 \%$ ) and exploration of the odor source was recorded 34,35 . THC (1 mg per $\mathrm{kg}$ ) decreased the threshold of odor detection (Fig. 7a and Supplementary Table 3) and this effect was clearly correlated with successive food intake (Fig. 7b and Supplementary Table 3). THC is known to exert a biphasic effect on stimulated food intake ${ }^{10,11}$. Consistently, neither a lower nor a higher dose of THC (0.25 mg per kg and $1.75 \mathrm{mg}$ per $\mathrm{kg}$, respectively) altered food intake (Supplementary Fig. 8 and Supplementary Table 2), nor did they alter odor detection, with no correlation between these two behaviors (Supplementary Fig. 8 and Supplementary Table 2). Intra-GCL infusion of a sub-effective dose of DCS fully blocked the effect of $1 \mathrm{mg}$ per $\mathrm{kg}$ THC on odor detection and proportionally reduced the hyperphagic effect of the $\mathrm{CB}_{1}$ receptor agonist (Fig. 7c,d and Supplementary Table 3), suggesting that the effect of THC depends on local decrease of glutamatergic transmission. THC had no effect on odor detection in Glu-CB ${ }_{1}^{-l-}$ mice (Fig. 7e and Supplementary Table 3), and these mice displayed a spontaneous decrease of odor detection under vehicle conditions (Fig. 7e and Supplementary Table 3). Food intake in vehicle- or THC-treated Glu-CB${ }_{1}^{-/-}$mice and wild-type littermates was positively correlated with odor detection threshold, further suggesting a potential causal relationship between these two processes (Fig. $7 \mathbf{f}$ and Supplementary Table 3). Moreover, the inhibitor of the anandamidedegrading enzyme fatty acid amide hydroxylase (FAAH) URB597 (ref. 36) proportionally increased food intake and odor detection in a dose-dependent manner (Fig. 7g,h, Supplementary Fig. 8, and Supplementary Tables 2 and 3). Together, these data indicate that both pharmacological and physiological activation of $\mathrm{CB}_{1}$ receptors in the GCL promote odor detection and proportionally increase food intake in fasted mice.

\section{Cannabinoids modulate synaptic activity in the MOB}

These genetic and pharmacological data indicate that (endo)cannabinoid signaling in the MOB reduces corticofugal glutamatergic transmission in the olfactory bulb to eventually promote food intake. However, genetic and pharmacological methods cannot provide direct evidence of such a mechanism. To directly test the effect of cannabinoid signaling on glutamatergic transmission from the AON/APC to the MOB, we adopted a combination of optogenetic stimulation of these terminals with local drug treatments and electrophysiological recordings in the MOB of awake head-fixed wild-type mice. An AAV containing the photoactivable Channelrhodopsin-2 
fused to mCherry (ChR2-mCherry $)^{37}$ was injected into the AON/APC of wild-type mice to obtain AON/APC-ChR2 mice, which express ChR2 mainly in the GCL (Fig. 8a). We recorded extracellular field excitatory postsynaptic potentials (fEPSPs) in the GCL of AON/APCChR2 mice in response to local light stimulation (Fig. 8b,c). Local injection of the $\mathrm{CB}_{1}$ receptor agonist WIN 55,212-2 (WIN, $4.2 \mathrm{ng}$ ) induced a strong decrease in the amplitude of the light-evoked fEPSPs (-61.4 \pm 4.5\%; Fig. 8c,d and Supplementary Table 3) without affecting spontaneous field activities such as gamma oscillations $(40-100 \mathrm{~Hz}$; change in gamma power, $+2.7 \pm 8.9 \%, P=0.28$, paired $t$ test). Thus, cannabinoid signaling can suppress glutamatergic transmission from AON/APC projections onto the MOB.

We next examined the effect of WIN on the activity of mitral cell projection neurons in response to the photoactivation of AON/APC axon terminals. We recorded spontaneous mitral cell single-unit firing activity (Fig. 8e) in response to light train stimulation with increasing frequencies up to continuous light stimulation. We observed that patterned AON/APC axon stimulation mainly inhibited mitral cell spontaneous firing in a frequency-dependent manner (Fig. 8f,g and Supplementary Table 3), suggesting that AON/APC cortical feedback mostly induces feedforward inhibition onto mitral cell ${ }^{19,20}$. Notably, local infusion of WIN decreased the magnitude of light-evoked feedforward inhibition of mitral cells firing without affecting mitral cell spontaneous firing rate (Fig. 8f,g and Supplementary Table 3). Thus, $\mathrm{CB}_{1}$ receptor activation selectively reduces the cortical inhibition of mitral cell spiking activity.

\section{DISCUSSION}

Hunger is a physiological condition driving the search for and ingestion of food. Our results suggest that $\mathrm{CB}_{1}$ receptor-dependent control of olfactory processes has a determinant role in coupling this internal state with the execution of the behavior (Supplementary Fig. 9).

When mice are fed standard chow, the control of cortical glutamatergic transmission by $\mathrm{CB}_{1}$ receptors is dispensable for the modulation of food intake in non-fasting conditions ${ }^{11}$. This suggests that specific factors associated with fasting likely trigger the hyperphagic function of the endocannabinoid system in these circuits. Feedingrelated molecules, such as ghrelin, orexins or leptin, which alter food intake and olfactory processes ${ }^{6,7}$, might participate in this $\mathrm{CB}_{1}$ receptor-dependent mechanism. In addition, a lack of specific nutrients 9 might induce $\mathrm{CB}_{1}$ receptor potentiation of olfactory processes. On the other hand, $\mathrm{CB}_{1}$ receptors located on cortical glutamatergic neurons determine the ingestion of novel palatable food in non-fasting conditions ${ }^{11}$. Although we did not test this condition, it will be interesting to extend the involvement of olfactory processes to different modalities of stimulated food intake, such as exposure to palatable food, deprivation of specific nutrients or hormonal treatments. Indeed, our electrophysiological in vivo recordings, performed in non-fasted mice, revealed that cannabinoids can decrease glutamatergic centrifugal activity in these conditions, suggesting that additional endogenous (for example, negative energetic status) or exogenous factors (for example, palatability of the food) are necessary to translate the effect of cannabinoid signaling in the MOB network into increased sensory perception and food intake.

Hyperphagic doses of exogenous cannabinoids are able to modulate both olfactory habituation and odor detection. However, the lack of a spontaneous phenotype in Glu- $C B_{1}^{-1-}$ mice in olfactory habituation and the lack of clear correlations between habituation and successive food intake in individual mice suggests that this pharmacological effect might be unrelated to cannabinoid control of food intake. Conversely, olfactory detection, as measured by the odor threshold assay $^{34}$, is strongly correlated with food intake. Detection of lowconcentration odors was decreased in hypophagic $\mathrm{Glu}-\mathrm{CB}_{1}{ }^{-1-}$ mice and was augmented by increasing the endogenous levels of anandamide. Thus, these data suggest that the enhancement of olfactory detection is likely the main mechanism linking (endo)cannabinoid signaling in the olfactory bulb to increased food intake.

We used almond and banana to analyze odor habituation and detection. Despite the fact that these molecules are generally used as non-food-related odors for naive rodents ${ }^{33}$, we cannot exclude that their attractiveness and the (endo)cannabinoid-dependent control of their perception are a result of an innate link to food. Future experiments will be needed to determine whether the (endo)cannabinoiddependent potentiation of olfactory processes and food intake acts on different odor categories, such as neutral or aversive essences.

Olfactory processes are generally considered to be weaker determinants of behavior in humans than in animals. However, this concept might be biased by the fact that olfactory information is processed at lower conscious levels than other sensory inputs in humans. In fact, humans make important decisions unconsciously using olfaction. For instance, partner selection is influenced by unconscious olfaction ${ }^{38}$ and odorant cues can alter visual perception ${ }^{39}$. Food intake disorders are often associated with an impaired sense of smell ${ }^{40-42}$, suggesting causal relationships between these processes. Cannabinoids alter both hunger and smell in humans ${ }^{10,12}$. To the best of our knowledge, a direct causal relationship between these two effects of cannabinoids has not been shown in humans, and specific experiments should be performed to test this hypothesis.

We found that $\mathrm{CB}_{1}$ receptor signaling in the olfactory bulb increases odor detection and proportionally promotes food intake, thereby linking hunger, olfaction and food intake (Supplementary Fig. 9). These functions of $\mathrm{CB}_{1}$ receptors are exerted by the presynaptic inhibition of glutamatergic transmission from cortical projections to the MOB. Two recent optogenetic studies revealed the precise functional connections between cortical olfactory areas and the $\mathrm{MOB}^{19,20}$. In particular, a previous study ${ }^{19}$ showed that the projections from AON impinge mainly onto granule cells and partly onto mitral cells of the MOB. However, mitral cells also receive a strong di-synaptic inhibition via granule cells ${ }^{19}$. These data are consistent with our c-Fos expression study showing that the inhibitory effect of $\mathrm{CB}_{1}$ receptor signaling on glutamatergic transmission during fasting led to a decrease of neuronal activity in granule cells of the MOB. An alternative possibility is that activation of $\mathrm{CB}_{1}$ receptors in the $\mathrm{MOB}$ might indirectly affect glutamatergic transmission via different mechanisms. However, our optogenetic in vivo electrophysiological recordings in awake mice directly demonstrate that cannabinoids can decrease excitatory local field potentials induced by centrifugal glutamatergic activity mainly onto inhibitory feedforward granule cells ${ }^{19}$, thereby dis-inhibiting the activity of mitral cells. Nevertheless, our c-Fos data did not show higher numbers of fasting-induced activated mitral cells in wild-type or Glu-CB ${ }_{1}^{-/-}$mice, which could be expected by the decrease in feedforward inhibition. This could be a result of the opposite simultaneous effect of $\mathrm{CB}_{1}$ receptor activation on glutamatergic centrifugal terminals onto granule cells (decreasing feedforward inhibition of mitral cells) and on direct projections to mitral cells ${ }^{19}$ (decreasing excitation of these neurons). Indeed, Glu- $\mathrm{CB}_{1}^{-/-}$and AON/APC$\mathrm{CB}_{1}{ }^{-1-}$ mice present a slight decrease of $\mathrm{CB}_{1}$ protein expression in the IPL, where corticofugal projections likely synapse onto mitral cells ${ }^{18,19}$. Thus, fasting and endocannabinoid signaling might determine the activation of specific network patterns linked to olfactory control of food intake without altering the total number of activated mitral cells. Recent data suggest that cannabinoid effect on inhibitory 
synaptic activity in the periglomerular area of the MOB might regulate olfactory processes ${ }^{13}$. However, the participation of periglomerular cells in (endo)cannabinoid control of food intake in our experimental conditions is unlikely. In fact, none of our manipulations altered the expression of $\mathrm{CB}_{1}$ receptors or $\mathrm{c}$-Fos in this area. Thus, the most parsimonious interpretation of our data is that activation of $\mathrm{CB}_{1}$ receptors on terminals of feedback cortical centrifugal glutamatergic neurons in the MOB directly reduced the excitatory drive onto granule cells, thereby regulating mitral cell activity to eventually increase odor detection and food intake (Supplementary Fig. 9).

The effects of THC on odor detection might be based on alterations of memory processes ${ }^{43}$. However, higher doses of THC are usually needed to substantially alter memory performance in rodents. For instance, the $1 \mathrm{mg}$ per $\mathrm{kg}$ hyperphagic dose of THC does not affect object recognition memory in either the long-term ${ }^{44}$ or short-term version of this task (A. Busquets-García, R. Maldonado, A. Ozaita, personal communication). Thus, although a memory component cannot be excluded, cannabinoid-induced alterations of memory and odor processing likely rely on distinct mechanisms and circuits. Another possibility is that THC might increase the motivation of the individuals ${ }^{45}$ to explore the odor source. However, this is rather unlikely, as the enhancing effect of THC in odor source exploration in our detection experiments is present only at lower odor concentrations $(0.001 \%$ and $0.01 \%)$, whereas it vanishes at the highest concentration $(0.1 \%)$. If THC increased the motivation to explore the odor source, this effect should logically be present at any odor concentration. Thus, despite the fact that memory and motivational confounders cannot be completely ruled out, the data strongly suggest a primary effect of (endo)cannabinoids on odor perception in our experimental conditions.

In conclusion (Supplementary Fig. 9), we found that the endocannabinoid-mediated control of cortical glutamatergic transmission in the olfactory bulb links an internal state (hunger) to sensory processing (olfaction) and, eventually, to behavior (food intake). Our results might also contribute to new conceptual frameworks for tackling pathological states. Indeed, altered sensory processes characterize several relevant food intake-related diseases, such as obesity, cachexia and anorexia ${ }^{40-42}$. Thus, specific interference with $\mathrm{CB}_{1}$ receptor-dependent hunger-olfaction-food intake circuits will likely help contrasting symptoms and development of these pathological conditions.

\section{METHODS}

Methods and any associated references are available in the online version of the paper.

Note: Any Supplementary Information and Source Data files are available in the online version of the paper.

\section{ACKNOWLEDGMENTS}

We thank D. Gonzales, N. Aubailly and all of the personnel of the Animal Facility of the NeuroCentre Magendie for mouse care and genotyping, A. Desprez for help with the odor task set-up, D. Herrera and S. Rahayel (NutriBrain School 2012) for help with some experiments, all of the members of the Marsicano laboratory for useful discussions, A. Bacci, D. Cota, V. Deroche and M. Valley for critically reading the manuscript, and K. Deisseroth (Stanford University) and B.L. Roth (University of North Carolina) for providing the plasmids coding for ChR2 and DREADD, respectively. This work was supported by INSERM (G.M.), EU-Fp7 (REPROBESITY, HEALTH-F2-2008-223713, G.M.), European Research Council (ENDOFOOD, ERC-2010-StG-260515, G.M.), Fondation pour la Recherche Medicale (FRM-DRM-20101220445, G.M.), Region Aquitaine (G.M.), LABEX BRAIN (ANR-10-LABX-43), Fyssen Foundation (E.S.-G.), EMBO Post-doc Fellowship (L.B.), RTA, I.S. Carlos III (RD12/0028/0004, P.G.), Basque Country Government BCG IT764-13 (P.G.), University of the Basque Country UFI11/41 (P.G.),
MINECO BFU2012-33334 (P.G.), Postdoctoral Specialization Contract from the University of the Basque Country UPV/EHU (L.R.), MINECO SAF2012-35759 (M.G.), Deutsche Forschungsgemeinschaft (SFB-TRR 58, B.L. and H.-C.P.), CONACyT (E.S.-G.). The Lledo laboratory is part of the École des Neurosciences de Paris Ile-de-France network, a member of the Bio-Psy Labex and is supported partially by "AG2R-La-Mondiale".

\section{AUTHOR CONTRIBUTIONS}

E.S.-G., G.F., P.-M.L. and G.M. designed the experiments. E.S.-G., L.B., L.R., G.L., C.M., M.B., S.R., F.R., T.D., I.M., T.W., A.C., A.N., A.W., A.P.C., D.V. and P.V. performed the experiments. H.-C.P. provided reagents. E.S.-G., L.B., L.R., G.L., F.M., B.L., M.G., C.Q., H.G., G.F., P.-M.L., P.G. and G.M. analyzed the data. E.S.-G., and G.M. wrote the manuscript. All of the authors edited the manuscript.

\section{COMPETING FINANCIAL INTERESTS}

The authors declare no competing financial interests.

Reprints and permissions information is available online at http://www.nature.com/ reprints/index.html.

1. Kato, H.K., Chu, M.W., Isaacson, J.S. \& Komiyama, T. Dynamic sensory representations in the olfactory bulb: modulation by wakefulness and experience. Neuron 76, 962-975 (2012).

2. Meissner, K. \& Wittmann, M. Body signals, cardiac awareness, and the perception of time. Biol. Psychol. 86, 289-297 (2011).

3. Bechara, A., Damasio, H., Tranel, D. \& Damasio, A.R. The lowa Gambling Task and the somatic marker hypothesis: some questions and answers. Trends Cogn. Sci. 9 159-162; discussion 162-154 (2005).

4. Goetzl, F.R. \& Stone, F. Diurnal variations in acuity of olfaction and food intake. Gastroenterology 9, 444-453 (1947)

5. Cameron, J.D., Goldfield, G.S. \& Doucet, E. Fasting for $24 \mathrm{~h}$ improves nasa chemosensory performance and food palatability in a related manner. Appetite $\mathbf{5 8}$ 978-981 (2012).

6. Julliard, A.K. et al. Changes in rat olfactory detection performance induced by orexin and leptin mimicking fasting and satiation. Behav. Brain Res. 183, 123-129 (2007).

7. Tong, J. et al. Ghrelin enhances olfactory sensitivity and exploratory sniffing in rodents and humans. J. Neurosci. 31, 5841-5846 (2011).

8. Albrecht, J. et al. Olfactory detection thresholds and pleasantness of a food-related and a non-food odor in hunger and satiety. Rhinology 47, 160-165 (2009).

9. DiPatrizio, N.V. \& Piomelli, D. The thrifty lipids: endocannabinoids and the neural control of energy conservation. Trends Neurosci. 35, 403-411 (2012).

10. Pagotto, U., Marsicano, G., Cota, D., Lutz, B. \& Pasquali, R. The emerging role of the endocannabinoid system in endocrine regulation and energy balance. Endocr. Rev. 27, 73-100 (2006).

11. Bellocchio, L. et al. Bimodal control of stimulated food intake by the endocannabinoid system. Nat. Neurosci. 13, 281-283 (2010).

12. Tart, C.T. Marijuana intoxication common experiences. Nature 226, 701-704 (1970).

13. Wang, Z.J., Sun, L. \& Heinbockel, T. Cannabinoid receptor-mediated regulation of neuronal activity and signaling in glomeruli of the main olfactory bulb. J. Neurosci. 32, 8475-8479 (2012)

14. Kawamura, Y. et al. The CB1 cannabinoid receptor is the major cannabinoid receptor at excitatory presynaptic sites in the hippocampus and cerebellum. J. Neurosci. 26, 2991-3001 (2006).

15. Marsicano, G. \& Kuner, R. Anatomical distribution of receptors, ligands and enzymes in the brain and the spinal cord: circuitries and neurochemistry. in Cannabinoids and the Brain (ed. Kofalvi, A.) 161-202 (Springer, New York, 2008).

16. Steindel, F. et al. Neuron type-specific cannabinoid-mediated G protein signaling in mouse hippocampus. J. Neurochem. 124, 795-807 (2013).

17. Davis, B.J. \& Macrides, F. The organization of centrifugal projections from the anterior olfactory nucleus, ventral hippocampal rudiment, and piriform cortex to the main olfactory bulb in the hamster: an autoradiographic study. J. Comp. Neurol. 203, 475-493 (1981).

18. Shepherd, G.M.C.W.R. \& Greer, C.A. Olfactory bulb. in The Synaptic Organization of the Brain (ed. Shepherd, G.M.) 165-216 (Oxford University Press, Oxford (UK), 2004).

19. Markopoulos, F., Rokni, D., Gire, D.H. \& Murthy, V.N. Functional properties of cortical feedback projections to the olfactory bulb. Neuron 76, 1175-1188 (2012).

20. Boyd, A.M., Sturgill, J.F., Poo, C. \& Isaacson, J.S. Cortical feedback control of olfactory bulb circuits. Neuron 76, 1161-1174 (2012).

21. Marinelli, S., Pacioni, S., Cannich, A., Marsicano, G. \& Bacci, A. Self-modulation of neocortical pyramidal neurons by endocannabinoids. Nat. Neurosci. 12 1488-1490 (2009).

22. Marsicano, G. \& Lutz, B. Expression of the cannabinoid receptor CB1 in distinct neuronal subpopulations in the adult mouse forebrain. Eur. J. Neurosci. 11, 4213-4225 (1999).

23. Monory, K. et al. The endocannabinoid system controls key epileptogenic circuits in the hippocampus. Neuron 51, 455-466 (2006). 
24. Kano, M., Ohno-Shosaku, T., Hashimotodani, Y., Uchigashima, M. \& Watanabe, M. Endocannabinoid-mediated control of synaptic transmission. Physiol. Rev. 89, 309-380 (2009).

25. Piomelli, D. The molecular logic of endocannabinoid signaling. Nat. Rev. Neurosci. 4, 873-884 (2003).

26. Di Marzo, V. et al. Leptin-regulated endocannabinoids are involved in maintaining food intake. Nature 410, 822-825 (2001).

27. Marsicano, G. et al. CB1 cannabinoid receptors and on-demand defense against excitotoxicity. Science 302, 84-88 (2003).

28. Monory, K. et al. Genetic dissection of behavioural and autonomic effects of Delta(9)-tetrahydrocannabinol in mice. PLoS Biol. 5, e269 (2007).

29. Ruehle, S. et al. Cannabinoid CB1 receptor in dorsal telencephalic glutamatergic neurons: distinctive sufficiency for hippocampus-dependent and amygdala-dependent synaptic and behavioral functions. J. Neurosci. 33, 10264-10277 (2013).

30. Goebbels, S. et al. Genetic targeting of principal neurons in neocortex and hippocampus of NEX-Cre mice. Genesis 44, 611-621 (2006).

31. Krashes, M.J. et al. Rapid, reversible activation of AgRP neurons drives feeding behavior in mice. J. Clin. Invest. 121, 1424-1428 (2011).

32. Rogan, S.C. \& Roth, B.L. Remote control of neuronal signaling. Pharmacol. Rev. 63, 291-315 (2011)

33. Yang, M. \& Crawley, J.N. Simple behavioral assessment of mouse olfaction. Curr. Protoc. Neurosci. Ch. 8, Unit 824 (2009).

34. Witt, R.M., Galligan, M.M., Despinoy, J.R. \& Segal, R. Olfactory behavioral testing in the adult mouse. J. Vis. Exp. published online, doi:10.3791/949 (28 January 2009).

35. Sánchez-Andrade, G., James, B.M. \& Kendrick, K.M. Neural encoding of olfactory recognition memory. J. Reprod. Dev. 51, 547-558 (2005).
36. Mor, M. et al. Cyclohexylcarbamic acid 3'- or 4'-substituted biphenyl-3-yl esters as fatty acid amide hydrolase inhibitors: synthesis, quantitative structure-activity relationships, and molecular modeling studies. J. Med. Chem. 47, 4998-5008 (2004).

37. Zhang, F. et al. Optogenetic interrogation of neural circuits: technology for probing mammalian brain structures. Nat. Protoc. 5, 439-456 (2010).

38. Jacob, S., McClintock, M.K., Zelano, B. \& Ober, C. Paternally inherited HLA alleles are associated with women's choice of male odor. Nat. Genet. 30, 175-179 (2002).

39. Zhou, W., Jiang, Y., He, S. \& Chen, D. Olfaction modulates visual perception in binocular rivalry. Curr. Biol. 20, 1356-1358 (2010).

40. Palouzier-Paulignan, B. et al. Olfaction under metabolic influences. Chem. Senses 37, 769-797 (2012).

41. Brisbois, T.D., Hutton, J.L., Baracos, V.E. \& Wismer, W.V. Taste and smell abnormalities as an independent cause of failure of food intake in patients with advanced cancer-an argument for the application of sensory science. J. Palliat. Care 22, 111-114 (2006).

42. Aschenbrenner, K., Scholze, N., Joraschky, P. \& Hummel, T. Gustatory and olfactory sensitivity in patients with anorexia and bulimia in the course of treatment. J. Psychiatr. Res. 43, 129-137 (2008).

43. Marsicano, G. \& Lafenetre, P. Roles of the endocannabinoid system in learning and memory. Curr. Top. Behav. Neurosci. 1, 201-230 (2009).

44. Puighermanal, E. et al. Cannabinoid modulation of hippocampal long-term memory is mediated by mTOR signaling. Nat. Neurosci. 12, 1152-1158 (2009).

45. Maldonado, R., Valverde, O. \& Berrendero, F. Involvement of the endocannabinoid system in drug addiction. Trends Neurosci. 29, 225-232 (2006). 


\section{ONLINE METHODS}

Mice. All experimental procedures were approved by the Committee on Animal Health and Care of INSERM and French Ministry of Agriculture and Forestry (authorization number, 3306369). Maximal efforts were made to reduce the suffering and the number of mice used. Male mice, aged 2-5 months, were maintained under standard conditions with food and water ad libitum. $C B_{1}$-flox and Glu- $\mathrm{CB}_{1}^{-1-}$ mice were obtained, maintained and genotyped as described ${ }^{11,27,23}$.

Rescue lines were generated as described ${ }^{29}$. Briefly, to generate the Stop- $C B_{1}$ mouse line, the endogenous $C B_{1}$ gene (also known as $C n r 1$ ) was silenced by insertion of a loxP-flanked stop cassette in the $5^{\prime} \mathrm{UTR}$ of the $\mathrm{CB}_{1}$ receptor start codon ${ }^{29}$. To generate the $C B_{1}$-RS mouse line for global rescue of $\mathrm{CB}_{1}$ receptor expression, the Stop- $C B_{1}$ line was crossed with a Cre-deleter mouse line $(\text { EIIa-Cre })^{46}$. To generate the Glu- $C B_{1}$-RS mouse line for a selective rescue of $\mathrm{CB}_{1}$ receptors on cortical glutamatergic neurons, Stop- $C B_{1}$ mice were crossed with a mouse line expressing Cre recombinase under the regulatory elements of the Nex gene (also known as Neurod6), which is the same mouse line used to obtain Glu- $\mathrm{CB}_{1}{ }^{-/-}$mice ${ }^{23,29}$. Mutant mice were in a mixed genetic background with predominance of $\mathrm{C} 57 \mathrm{BL} / 6 \mathrm{~N}\left(\mathrm{CB}_{1}\right.$-flox and $\mathrm{Glu}-\mathrm{CB}_{1}^{-1-}, 6$ or 7 generations) or C57BL/6J (Stop- $C B_{1}, C B_{1}$-RS and Glu- $C B_{1}$-RS).

All mice used in experiments involving mutant mice were littermates, except in the experiments depicted in Figure $\mathbf{4} \mathbf{b}$, where $C B_{1}$-RS mice originated from independent breedings. Wild-type C57BL/6N mice were purchased from Janvier (France). Experimenters were always blind to genotypes and/or treatments.

Virus generation. Control and CRE virus constructs were prepared as described before $^{23}$. hM3Dq fused to mCherry (kindly provided by B.L. Roth, University of North Carolina), or mCherry alone for the control virus, were subcloned into an AAV expression vector (kindly provided by K. Deisseroth, Stanford University) with the minimal promoter of calcium calmodulin kinase II $\alpha$ (CaMKII $\alpha$-P) by using standard molecular cloning techniques. For behavioral experiments, rAAV were of a mixed serotype AAV1/AAV2 and were generated by calcium phosphate transfection of HEK 293T cells and purified as described before ${ }^{23}$. For electrophysiological studies, high titer AAV2/9 vectors $\left(3 \times 10^{13}\right.$ genome copies per ml, qPCR) containing pAAV-hSyn-ChR2(H134R)-mCherry (kindly provided by K. Deisseroth, Addgene \#26976) was produced by the INSERM IRT1 Vector platform (Nantes, http://www.vectors.univ-nantes.fr/).

Surgery and drug/virus administration. Mice were anesthetized by intraperitoneal injection of a mixture of ketamine (100 mg per $\mathrm{kg}$, Imalgene 500, Merial) and xylazine (10 mg per kg, Rompun, Bayer) and placed into a stereotaxic apparatus (David Kopf Instruments) with mouse adaptor and lateral ear bars. For intra-olfactory bulb injections of drugs, mice were bilaterally implanted with 3-mm stainless steel guide cannulae (Plastics One) targeting the olfactory bulb with the following coordinates: AP $+4.2, \mathrm{~L} \pm 1.0, \mathrm{DV}-2.0$, according to Paxinos and Franklin ${ }^{47}$. Guide cannulae were secured in place with dental cement. Mice were allowed to recover for 7-10 $\mathrm{d}$ in individual cages before the beginning of the experiments. Mice were weighed daily and individuals that failed to regain the pre-surgery body weight were excluded from following experiments. For viral intra-AON delivery, mice were submitted to stereotaxic surgery (as above) and AAV vectors were injected with the help of a microsyringe attached to a pump (UMP3-1, World Precision Instruments). Mice were injected with AAV-Cre or AAV-empty vector directly into the $\mathrm{AON}(0.5 \mu \mathrm{l}$ per injection), with the following coordinates: $\mathrm{AP}+2.6, \mathrm{~L} \pm 0.5, \mathrm{DV}-3.5$, and into the APC: $\mathrm{AP}+2.3, \mathrm{~L} \pm 1.5, \mathrm{DV}$ -3.7 , according to Paxinos and Franklin ${ }^{47}$. For electrophysiological experiments, mice were injected in the AON $(\mathrm{AP},+2.6$; $\mathrm{ML}, \pm 1.2 ; \mathrm{DV},-3.5 ; 0.1 \mu \mathrm{l})$ and $\mathrm{APC}$ (AP, $+2.1 ; \mathrm{ML}, \pm 1.85 ; \mathrm{DV},-3.6 ; 0.4 \mu \mathrm{l})$ using pulled glass capillaries connected to a Nanoinjector System (Drummond). Mice were used for experiments 5 weeks after injection to get an optimal deletion or re-expression, depending of the mouse line, of $\mathrm{CB}_{1}$ receptors in olfactory circuits. $\mathrm{CB}_{1}$ deletion and re-expression was verified by in situ hybridization and/or immunohistochemistry (see below). Mice injected with DREAAD or mCherry virus went for a washout period of 1 week after behavioral experiments. Then they were injected with saline or CNO and perfused 30 min later. Brains were post fixed and then slices of the MOB and the AON were made at $20 \mu \mathrm{m}$ on a cryostat (Leica) and mounted on gelatin-coated microscope slides. Some slides were just counterstained with DAPI for correct visualization of red fluorescence/injection site. Other slides were processed for P-CREB immunohistochemistry by using rabbit antibody to P-CREB (1:500,
Cell Signaling, mAb No. 9198) and EnVision FLEX kit (DAKO) according to manufacturer instructions.

Electrophysiology. 1 month after intra-AON/APC injection, anesthetized mice were implanted with a L-shaped metal bar fixed with dental acrylic to the caudal part of the skull. After recovery ( $7 \mathrm{~d}$ ), implanted mice were progressively habituated to stay quiet while head-fixed $(7 \mathrm{~d}) .1 \mathrm{~d}$ before recording, the mouse was anesthetized and the bone covering one of the two bulbs was thinned and removed using a microdrill and then protected with a silicone sealant (KwikCast, WPI). Mitral cell spiking activity and GCL local field potential (LFP) were recorded in the ventral and dorsal part of the bulb using an array of four 3-M $\Omega$ tungsten electrodes (FHC, tip distance $=400-500 \mu \mathrm{m}$ ) glued parallel to a miniature cannula (polyimide tubing, 0.0035 inches, Neuralynx) connected to a $10-\mu \mathrm{l}$ Hamilton syringe for subsequent drug infusion. Light stimulation was performed using an optic fiber (multimode, $430-\mu \mathrm{m}$ diameter, NA 0.39, Thorlabs) coupled to a DPSS laser ( $473 \mathrm{~nm}, 150 \mathrm{~mW}$, CNI Lasers) via a custom-built fiber launcher and controlled by PS-H-LED laser driver connected to the CED interface. After lowering the electrodes into the craniotomy and positioning the optic fiber on the surface of the dura, a drop of Kwik-Cast was applied to protect the brain during the recording and to improve recordings stability. Light stimulation consisted of a 1-s train stimulus at different frequency (5-ms light pulse, 40-mW output intensity, $10 \mathrm{~Hz}$ for fEPSP analysis, $10-100 \mathrm{~Hz}$ for mitral cell activity) or continuous light stimulation and was presented every $10 \mathrm{~s}$ for ten sweeps. Awake recording sessions lasted $2-3 \mathrm{~h}$ and mice were given a $0.2 \mathrm{ml}$ of a $15 \%$ glucose solution (wt/vol) through a plastic pipette every $30 \mathrm{~min}$. We performed two recording sessions per mice (one per hemisphere), which were made at least $2 \mathrm{~d}$ apart. The craniotomy was cleaned and covered with Kwik-Cast between sessions. Both LFPs and spiking activity were preamplified (unitary gain head-stage, WPI), amplified ( $\times 10,000$, WPI), altered (1-300 Hz for LFP, $0.3-8 \mathrm{kHz}$ for spikes) and digitized at $25 \mathrm{kHz}$ (Micro1401-3 A/D interface, CED). The identity of mitral cell units were established on the basis of several criteria: 1) stereotaxic coordinates of the MCL, 2) decrease in the gamma oscillation amplitude in the MCL, compared with the LFP recorded in the GCL or EPL, where the current source/sink of gamma oscillation are localized ${ }^{48}, 3$ ) increase in background spiking activity in a narrow band of 100-150 $\mu \mathrm{m}$ corresponding to the MCL, and 4) typical spontaneous activity patterns coarsely time-locked to the respiration rhythm ${ }^{49}$. Signals were continuously recorded from $30 \mathrm{~min}$ before and $80 \mathrm{~min}$ after local acute microinfusion through the miniature cannula lying $\sim 300 \mu \mathrm{m}$ above the tip of the electrodes (injection volume $=0.1 \mu \mathrm{l}$, speed $=0.05 \mu \mathrm{min}^{-1}$ ). Spike detection, spike sorting, spike clustering function and spike waveform analysis were performed using Spike2 software (CED) followed by a manual adjustment of the clusters. For single-unit validation, all sorted cells displaying more than $1 \%$ of their interspike intervals below a 3.5-ms refractory period were discarded from the analysis. Careful attention was also taken to discard any unit that showed some significant changes in spike amplitude or waveform caused by the local infusion of drugs. For light-evoked field potentials, the absolute fEPSP peak amplitude of the first pulse was measured and averaged over the ten sweeps. Fast-fourier transform (Hanning-window, 2.44- $\mathrm{Hz}$ resolution) was used to obtain the spectral power of the gamma oscillation band $(40-100 \mathrm{~Hz})$ from 1-minlong epoch before and $\sim 10 \mathrm{~min}$ after injection. For mitral cell activity, peri-light stimulus histograms were calculated for each stimulation pattern and the mean firing rate during the 1-s stimulation was compared with the mean firing rate in the 1-s period preceding the light stimulation. For post hoc histological analysis, mice were intracardially perfused (ice-cold $4 \%$ paraformaldehyde (wt $/ \mathrm{vol}$ ) in $0.1 \mathrm{M}$ phosphate buffer). The brain was removed and postfixed in the same fixative overnight. Brain sections were cut on a vibratome (40- $\mu \mathrm{m}$-thick slices), rinsed in phosphate-buffered solution, counterstained with DAPI, mounted with a fluorescence mounting medium (Mowiol) and observed with a confocal microscope (LSM 700, Zeiss).

Drugs. All drugs were purchased from Sigma-Aldrich, except AM251 and WIN55212-2, which were purchased from Tocris, and URB597, which was purchased from Cayman. For intraperitoneal injections, the vehicle for THC was sterile saline solution $(92 \%, \mathrm{vol} / \mathrm{vol})$, ethanol $(4 \%, \mathrm{vol} / \mathrm{vol})$ and cremophore ( $4 \%, \mathrm{vol} / \mathrm{vol}$ ), whereas the vehicle for URB597 was $5 \% \mathrm{DMSO}$ (vol/vol) in saline. Drugs or vehicle were injected $30 \mathrm{~min}$ before refeeding (see below) or olfactory tests (see below). For intra-MOB injections, AM251 was dissolved in a mixture of 
saline $(0.9 \% \mathrm{NaCl}, \mathrm{vol} / \mathrm{vol})$ with $10 \% \mathrm{DMSO}$ and $10 \%$ Chremophor EL, whereas DCS, MK801 and CNO were dissolved in saline solution. All drugs were prepared fresh just before the experiments.

Fasting-induced food intake. Mice were housed under a 12-h: 12-h dark/light cycle (light on 7 a.m., light off 7 p.m.). Before the experiments, mice were singly housed for at least $7 \mathrm{~d} .2 \mathrm{~h}$ after the light onset, mice were food deprived for $24 \mathrm{~h}$ and then given free access to a pre-weighed amount of standard chow (Standard Rodent Diet A03, SAFE). Food intake was recorded 1 and $2 \mathrm{~h}$ after refeeding ${ }^{11}$. Under these conditions, spillage of food was minimal. It was however controlled by inspection of litter and calculated as not eaten food. In these procedures, drugs were administered $30 \mathrm{~min}$ before refeeding, and pre-treatments, including CNO, were administered $15 \mathrm{~min}$ before drugs.

Olfactory tests. Olfactory tests were adapted according to refs. 33,50-52.

Olfactory habituation. Two different neutral ${ }^{33}$ odors were used during the test: benzaldehyde (almond) and isopentyl acetate (banana) (Sigma-Aldrich). The odors were diluted with mineral oil. For odor presentations, $5 \mu$ l of diluted odorant $(0.1 \%)$ or plain mineral oil were deposited onto filter paper and then placed inside a holder. Mice were tested after $24 \mathrm{~h}$ of fasting and from $4-8 \mathrm{~h}$ after the onset of the light cycle that corresponds to the same range used for assessing feeding behavior. Drug injections (immunoprecipitate and intra-MOB) were performed $30 \mathrm{~min}$ before the test. For testing, mice were placed into a plastic cage box (testing cage, identical to their home cage) without bedding or food, located in a room different of the housing room. The task consisted of 5-min odor presentations separated by 5 -min inter-trial intervals. In a given session, mice were first presented with the holder containing the mineral oil only. They were then presented with the first odorant during two successive trials (habituation). Subsequently, they were presented the second odorants (control odor) (data not shown). Exploration of the odor source was defined as directing the nose at a distance $<1 \mathrm{~cm}$ from the tip of the holder, with the vibrissae moving, and/or touching it with the nose. The exploration was not scored when the mouse was chewing the object. The testing cage was cleaned with ethanol $70 \%$ and water between the sessions. The two odorants used were presented according to a counterbalanced schedule. To evaluate odor thresholds, we used the same protocol, but only one odor was presented at different concentrations starting at $0.001 \%$ and then $0.01 \%$ and $0.1 \%$ subsequently. After testing, mice were returned to the housing room and replaced in their home cage with pre-weighed food. Then, food intake was measured after $1 \mathrm{~h}$.

Endocannabinoids measurements. Mice were killed under fasting or food ad libitum conditions. Brains were quickly removed and the olfactory bulb, hypothalamus and cerebellum dissected, flash frozen, and stored at $-80{ }^{\circ} \mathrm{C}$ until analysis. Measurements of AEA and 2-AG were carried out as previously described ${ }^{53}$. Briefly, tissues were homogenized and extracted with chloroform/ methanol/Tris- $\mathrm{HCl}(50 \mathrm{mM}, \mathrm{pH} 7.5,2: 1: 1, \mathrm{vol} / \mathrm{vol})$ containing internal deuterated standards (AEA-d4 and 2-AG-d5). Mass spectral analyses were performed on a TSQ Quantum triple quadrupole instrument (Thermo-Finnigan) equipped with an atmospheric pressure chemical ionization source and operating in positive ion mode. The amounts of anandamide were determined by isotope-dilution using a calibration curve. Endocannabinoid levels were then normalized by the weight of fresh tissue.

Immunohistochemistry. Mice were anesthetized with chloral hydrate (400 mg per kg body weight), transcardially perfused with phosphate-buffered solution ( $0.1 \mathrm{M}, \mathrm{pH} 7.4$ ) and then fixed by $500 \mathrm{ml}$ of $4 \%$ formaldehyde (wt/vol) prepared at $4{ }^{\circ} \mathrm{C}$. Serial coronal or sagittal vibrosections were cut at $40 \mu \mathrm{m}$ and collected in $0.1 \mathrm{M}$ phosphate-buffered solution ( $\mathrm{pH} 7.4$ ) at $20-22{ }^{\circ} \mathrm{C}$. Sections were preincubated in a blocking solution of $10 \%$ donkey serum, $0.1 \%$ sodium azide (wt/vol) and $0.3 \%$ Triton $\mathrm{X}-100$ (vol/vol) prepared in $0.1 \mathrm{M}$ phosphatebuffered solution for $30 \mathrm{~min}$ at $20-22^{\circ} \mathrm{C}$. Free-floating sections were incubated with goat polyclonal antibodies raised against a 31 amino acid $\mathrm{C}$-terminal sequence (NM007726) of mouse $\mathrm{CB}_{1}$ receptor $\left(\mathrm{CB}_{1}\right.$-Go-Af450-1, $2 \mu \mathrm{g} \mathrm{ml}^{-1}$, Frontier Science, 1-777-12) for $48 \mathrm{~h}$ at $4{ }^{\circ} \mathrm{C}$. The antibody was prepared in $10 \%$ donkey serum and phosphate-buffered solution containing $0.1 \%$ sodium azide and $0.5 \%$ Triton X-100. After several washes, the tissue was incubated with fluorescent antibody to goat conjugated to Alexa 488 (1:200, Jackson ImmunoResearch, cat. no. 305-546-003) for $4 \mathrm{~h}$ and then washed in $0.1 \mathrm{M}$ phosphate-buffered solution at $20-22^{\circ} \mathrm{C}$, before being incubated with DAPI $(1: 20,000)$ for $10 \mathrm{~min}$. Finally, sections were washed, mounted, dried and coverslipped with DPX (Fluka Chemie AG). The slides were analyzed with an epifluorescence Leica DM6000 microscope (Leica). For light microscopy, the same procedure was used, with the following modifications Briefly, the fixative solution to perfuse mice was made up of $4 \%$ formaldehyde (freshly depolymerized from paraformaldehyde), $0.2 \%$ picric acid and $0.1 \%$ glutaraldehyde (vol/vol) in $0.1 \mathrm{M}$ phosphate-buffered solution. Blocking solution was made of $10 \%$ normal horse serum (NHS, vol $/ \mathrm{vol}$ ), $0.1 \%$ sodium azide and $0.5 \%$ Triton $\mathrm{X}-100$ prepared in Tris- $\mathrm{HCl}$ buffered saline (TBS), and primary antibody was prepared in this blocking solution. After incubation with the primary antibody, tissue sections were incubated in a secondary biotinylated horse antibody to goat IgG (1:200, Vector Laboratories, cat. no. BA-9500). After washing, sections were processed by a conventional avidin-biotin peroxidase complex method (ABC Elite, Vector Laboratories). Tissue was incubated in the avidin-biotin complex (1:50) prepared in the washing solution for $1 \mathrm{~h}$ at $20-22{ }^{\circ} \mathrm{C}$. Then, sections were washed and incubated with $0.05 \%$ diaminobenzidine (wt/vol) in $0.1 \mathrm{M}$ phosphate-buffered solution with $0.5 \%$ Triton X-100 and $0.01 \%$ hydrogen peroxide ( $\mathrm{vol} / \mathrm{vol}$ ), for $5 \mathrm{~min}$ at $20-22^{\circ} \mathrm{C}$. Finally, tissue was mounted, dehydrated in graded alcohols $\left(50^{\circ}, 70^{\circ}, 96^{\circ}, 100^{\circ}\right)$ to xylol and coverslipped with DPX. Sections were observed and photographed with a light microscope Zeiss Axiophot. For $\mathrm{CB}_{1}$ detection by light microscopy after viral injection in the AON, we applied the same protocol described above with some modifications. To sum up, olfactory bulbs were dissected from non-perfused brains and directly placed in paraformaldehyde (4\%). After washing in $0.1 \mathrm{M}$ phosphate-buffered solution and cryoprotection with $15 \%$ and $30 \%$ sucrose, coronal sections were cut at $40 \mu \mathrm{m}$ in a cryotome, collected in $0.1 \mathrm{M}$ phosphatebuffered solution and incubated in $1 \%$ hydrogen peroxide in $0.1 \mathrm{M}$ phosphatebuffered solution for $30 \mathrm{~min}$ at $20-22^{\circ} \mathrm{C}$.

Analysis of $\mathrm{CB}_{1}$ expression in the olfactory bulb. $40-\mu \mathrm{m}$-thick olfactory bulb sections from mice of each condition (at least $n=3$ each) were analyzed. Image- $\mathrm{J}$ (version $1.43 \mathrm{u}$, US National Institutes of Health) was used to quantify $\mathrm{CB}_{1}$ immunolabeling density (mean gray value) in different layers of the MOB.

c-Fos. The protocol was identical as for $\mathrm{CB}_{1}$ immunofluorescence with some modifications. Primary antibody to c-Fos $(1: 2,000$, Santa Cruz Biotechnology, cat. no. sc-52) was incubated overnight at $4{ }^{\circ} \mathrm{C}$. After washing, the tissue was incubated with fluorescent antibody to rabbit conjugated to Alexa 555 (1:2,000, Invitrogen, cat. no. A-21428) for $4 \mathrm{~h}$. Sections were washed, mounted, dried and coverslipped. The slides were analyzed with an epifluorescence Leica DM6000 microscope (Leica).

Quantification of c-Fos expression in the olfactory bulb. c-Fos-positive cells were counted using the software Metamorph (V 7.0). All images were acquired (CoolSNAP HQ ${ }^{2}$, Photometrics) with the same exposition time. The image analysis system measure the optic density in a surface area, quantifying the number of cell nuclei in the area delimited by the drawn contour surrounding the GCL, MCL and glomerular layer according to an automated cell count. This method detects objects (cells) on basis of a group of pixels with values of optical density above the threshold, which are expressed as number of cells. In each section, the detection level (gray scaling) was chosen above the background level.

Electron microscopy. Mice were perfused with a fixative solution made up of $4 \%$ formaldehyde (freshly depolymerized from paraformaldehyde), $0.2 \%$ picric acid and $0.1 \%$ glutaraldehyde in $0.1 \mathrm{M}$ phosphate-buffered solution. Vibrosections $(40 \mu \mathrm{m})$ were preincubated in a blocking solution of $10 \%$ bovine serum albumin (BSA, vol $/ \mathrm{vol}$ ), $0.1 \%$ sodium azide and $0.02 \%$ saponin ( $\mathrm{vol} / \mathrm{vol}$ ) in TBS for $30 \mathrm{~min}$ at room temperature. Then they were incubated in the primary polyclonal goat antibody to $\mathrm{CB}_{1}$ as described above prepared in the blocking solution, but with $0.04 \%$ saponin, on a shaker for $2 \mathrm{~d}$ at $4{ }^{\circ} \mathrm{C}$. After several washes with $1 \%$ BSA in TBS, tissue sections were incubated in a secondary $1.4-\mathrm{nm}$ nanogold antigoat antibody (1:100, Fab' fragment, Nanoprobes) prepared in the same solution as the primary antibody for $3 \mathrm{~h}$ on a shaker at $20-22^{\circ} \mathrm{C}$. Then, tissue was washed overnight at $4{ }^{\circ} \mathrm{C}$ and postfixed in $1 \%$ glutaraldehyde for $10 \mathrm{~min}$. After several washes in double distilled water, gold particles were silver-intensified with a HQ Silver 
Kit (Nanoprobes) for $12 \mathrm{~min}$ in the dark. Then tissue was extensively washed in double distilled water and in $0.1 \mathrm{M}$ phosphate-buffered solution and osmicated in $1 \%$ osmium tetroxide ( $\mathrm{wt} / \mathrm{vol}$ ) for $20 \mathrm{~min}$. After washing in $0.1 \mathrm{M}$ phosphatebuffered solution, sections were dehydrated in graded alcohols $\left(50^{\circ}, 70^{\circ}, 96^{\circ}\right.$, $100^{\circ}$ ) to propylene oxide and embedded in Epon resin 812. 80-nm ultrathin sections were collected on mesh nickel grids, stained with $2.5 \%$ lead citrate for $20 \mathrm{~min}$ and examined in a PHILIPS EM208S electron microscope. Tissue preparations were photographed by using a digital camera coupled to the electron microscope. Figure compositions were made at 600 dots per inch (dpi). Labeling and minor adjustments in contrast and brightness were done using Adobe Photoshop (CS, Adobe Systems).

Electron micrographs were taken from grids ( $132-\mu \mathrm{m}$ side) containing silverintensified gold particles, all of them showing a similar labeling intensity indicating that selected areas were at the same depth. Furthermore, to avoid false negatives, only ultrathin sections in the first $1.5 \mu \mathrm{m}$ from the surface of the tissue block were examined. Positive labeling was considered if at least one immunoparticle was within approximately $30 \mathrm{~nm}$ from the plasmalemma. Metal particles on synaptic membranes were visualized and counted. Semi-quantification of immunogold labeling on unequivocally identified type-I and type-II synapses was performed one mouse of each genotype (wild-type, $\mathrm{Glu}-\mathrm{CB}_{1}^{---}$and $\mathrm{CB}_{1}^{-/-}$). Semiquantification of immunogold labeling on total synaptic terminals and on axon buttons forming type-I and type-II synapses was performed counting a total of 567 profiles from GCL of one mouse of each genotype (wild-type, 62 pictures; Glu- $C B_{1}^{-1-}, 27$ pictures; $C B_{1}^{-1-}, 35$ pictures). Briefly, $\mathrm{CB}_{1}$-immunopositive and $\mathrm{CB}_{1}$-immunonegative synaptic terminals were identified as described above and counted. Then, the percentage of $\mathrm{CB}_{1}$ immunolabeled terminals was calculated for each animal genotype. The same method was followed to obtain the proportion of $\mathrm{CB}_{1}$-immunopositive axon terminals forming unequivocal type-I and type-II synapses based on ultrastructural features.

In situ hybridization. The procedure was performed as described ${ }^{11,22}$. Mice were killed by cervical dislocation. Their brains were isolated, quickly frozen on dry ice and stored at $-80^{\circ} \mathrm{C}$ until sectioning in a cryostat $(14 \mu \mathrm{m}$, Microm HM $500 \mathrm{M}$, Microm Microtech). FITC-labeled riboprobes against mouse $\mathrm{CB}_{1}$ receptor and DIG-labeled riboprobes against mouse GAD65, VGluT1 and tyrosine hydroxylase were prepared as decribed ${ }^{1,14}$. For signal amplification, we used the
TSA Plus System Cyanine 3/Fluorescein (PerkinElmer). Blocking buffer TNB and wash buffer TNT were prepared according to the manufacturer's protocol. Slides were analyzed by epifluorescence microscopy (Leica).

Data collection. No statistical methods were used to pre-determine sample sizes, but they are similar to those reported in previous publications ${ }^{11,54}$. Data collection and analysis were performed blind to the conditions of the experiment. All mice were assigned randomly to the different experimental conditions.

Statistical analyses. Data were analyzed by Student's $t$ test or ANOVA (repeated, one-way and two-way) where appropriate. For ANOVA, only when significant effects of main factors were detected, post hoc analyses (Bonferroni's) were performed. However, as normality could not be calculated for all groups, non-parametric tests (Mann-Whitney or Kruskall-Wallis) were also used, which provided virtually the same results. For detailed statistical analysis see Supplementary Tables 1-3.

46. Lakso, M. et al. Efficient in vivo manipulation of mouse genomic sequences at the zygote stage. Proc. Natl. Acad. Sci. USA 93, 5860-5865 (1996).

47. Paxinos, G. \& Franklin, K.B.J. The Mouse Brain in Stereotaxic Coordinates (Academic Press, San Diego, 2001).

48. Neville, K.R. \& Haberly, L.B. Beta and gamma oscillations in the olfactory system of the urethane-anesthetized rat. J. Neurophysiol. 90, 3921-3930 (2003).

49. Rinberg, D. \& Gelperin, A. Olfactory neuronal dynamics in behaving animals. Semin. Cell Dev. Biol. 17, 454-461 (2006).

50. McNamara, A.M., Magidson, P.D., Linster, C., Wilson, D.A. \& Cleland, T.A. Distinct neural mechanisms mediate olfactory memory formation at different timescales. Learn. Mem. 15, 117-125 (2008).

51. Fadool, D.A. et al. Kv1.3 channel gene-targeted deletion produces "Super-Smeller Mice" with altered glomeruli, interacting scaffolding proteins, and biophysics. Neuron 41, 389-404 (2004).

52. Ferguson, J.N. et al. Social amnesia in mice lacking the oxytocin gene. Nat. Genet. 25, 284-288 (2000).

53. Lourenço, J., Matias, I., Marsicano, G. \& Mulle, C. Pharmacological activation of kainate receptors drives endocannabinoid mobilization. J. Neurosci. 31 , 3243-3248 (2011).

54. Bellocchio, L. et al. Activation of the sympathetic nervous system mediates hypophagic and anxiety-like effects of $\mathrm{CB} 1$ receptor blockade. Proc. Natl. Acad. Sci. USA 110, 4786-4791 (2013). 